\title{
Interventions in the alcohol server setting for preventing injuries (Review)
}

\author{
Ker K, Chinnock P
}
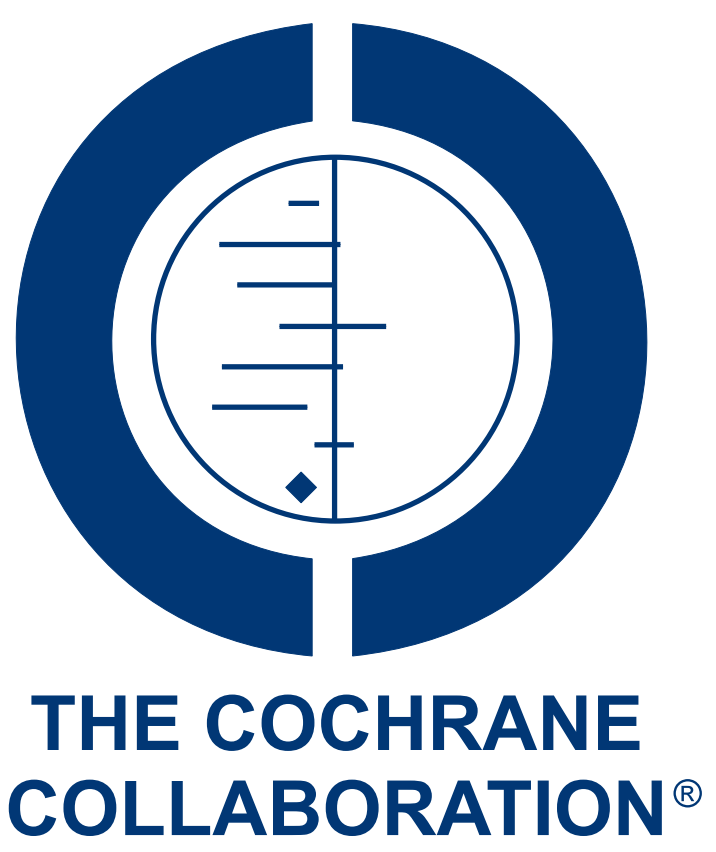

This is a reprint of a Cochrane review, prepared and maintained by The Cochrane Collaboration and published in The Cochrane Library 2006, Issue 2

\section{WILEY}




\section{TABLE OF CONTENTS}

ABSTRACT . . . . . . . . . . . . . . . . . . . . . . . . . . . . . . . . . . . . . . 1

PLAIN LANGUAGE SUMMARY . . . . . . . . . . . . . . . . . . . . . . . . . . . . . . . . . . . . . . .

BACKGROUND . . . . . . . . . . . . . . . . . . . . . . . . . . . . . . . . . . . . . 2

OBJECTIVES . . . . . . . . . . . . . . . . . . . . . . . . . . . . . . . . . . . . . . . . . . . . . . 44

CRITERIA FOR CONSIDERING STUDIES FOR THIS REVIEW . . . . . . . . . . . . . . . . . . . . . . . . . $\quad 4 \quad 4$

SEARCH METHODS FOR IDENTIFICATION OF STUDIES . . . . . . . . . . . . . . . . . . . . . . . . . . . . . 4

METHODS OF THE REVIEW . . . . . . . . . . . . . . . . . . . . . . . . . . . . . . . . 5

DESCRIPTION OF STUDIES . . . . . . . . . . . . . . . . . . . . . . . . . . . . . . . . . . . . . . 5

METHODOLOGICAL QUALITY . . . . . . . . . . . . . . . . . . . . . . . . . . . . . . . . 6

RESULTS . . . . . . . . . . . . . . . . . . . . . . . . . . . . . . . . . . . . . . . . . . .

DISCUSSION . . . . . . . . . . . . . . . . . . . . . . . . . . . . . . . . . . . . . . . . .

AUTHORS' CONCLUSIONS . . . . . . . . . . . . . . . . . . . . . . . . . . . . . . . . . . . . . . . . . . 13

POTENTIAL CONFLICT OF INTEREST . . . . . . . . . . . . . . . . . . . . . . . . . . . . . . . . 14

ACKNOWLEDGEMENTS . . . . . . . . . . . . . . . . . . . . . . . . . . . . . . . . . . . . 14

SOURCES OF SUPPORT . . . . . . . . . . . . . . . . . . . . . . . . . . . . . . . . . . . . . . . 14

REFERENCES . . . . . . . . . . . . . . . . . . . . . . . . . . . . . . . . . . . . 14

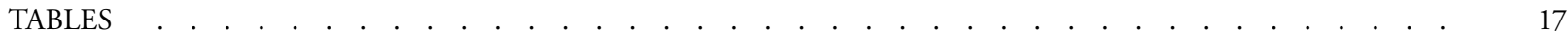

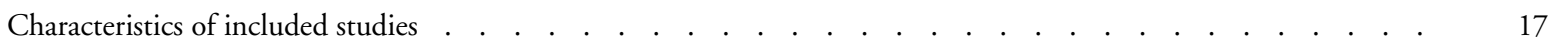

Characteristics of excluded studies . . . . . . . . . . . . . . . . . . . . . . . . . . . . . . . . . . . . .

ADDITIONAL TABLES . . . . . . . . . . . . . . . . . . . . . . . . . . . . . . . . . . . . . . . . . . . .

Table 01. Cochrane Injuries Group specialised register - search strategy . . . . . . . . . . . . . . . . . . . . 26

Table 02. CENTRAL - search strategy

Table 03. MEDLINE - search strategy

Table 04. EMBASE - search strategy

Table 05. PsycINFO - search strategy . . . . . . . . . . . . . . . . . . . . . . . . . . . . . . . . . . . . . . . 28

Table 06. SPECTR - search strategy _. . . . . . . . . . . . . . . . . . . . . . . . . . . . . . . . . . . . . 29

Table 07. SIGLE - search strategy . . . . . . . . . . . . . . . . . . . . . . . . . . . . . . . . . . . 29

Table 08. Methodological quality - allocation bias . . . . . . . . . . . . . . . . . . . . . . . . . . . . . .

Table 09. Methodological quality -confounders . . . . . . . . . . . . . . . . . . . . . . . . . . . . . . . .

Table 10. Methodological quality - blinding . . . . . . . . . . . . . . . . . . . . . . . . . . . $\quad$. 32

Table 11. Methodological quality - data collection methods . . . . . . . . . . . . . . . . . . . . . . . . . . . 33

Table 12. Methodological quality - withdrawals \& dropouts . . . . . . . . . . . . . . . . . . . . . . . . 35

Table 13. Methodological quality - intervention integrity . . . . . . . . . . . . . . . . . . . . . . . 35

Table 14. Methodological quality - follow-up . . . . . . . . . . . . . . . . . . . . . . . . . . . . 36

Table 15. Results - server training (injuries) . . . . . . . . . . . . . . . . . . . . . . . . . . . . . . . . . $\quad . \quad 37$

Table 16. Results - server training (behaviour) . . . . . . . . . . . . . . . . . . . . . . . . . . . . . . . . . $\quad$. 39

Table 17. Results - server training (knowledge) . . . . . . . . . . . . . . . . . . . . . . . . . . . . . . . 44

Table 18. Results - Health promotion interventions . . . . . . . . . . . . . . . . . . . . . . . . . . . 44

Table 19. Results - Drink driving prevention services _. . . . . . . . . . . . . . . . . . . . . . . . . . 45

Table 20. Results - Interventions targeting the server setting environment . . . . . . . . . . . . . . . . . . . 45

Table 21. Results - Server setting management/policy interventions . . . . . . . . . . . . . . . . . . . . . . . 46

GRAPHS AND OTHER TABLES . . . . . . . . . . . . . . . . . . . . . . . . . . . . . . . . . . . . . . . . . 46

INDEX TERMS . . . . . . . . . . . . . . . . . . . . . . . . . . . . . . . . . . . . . . . . . . . . . . . . 46

COVER SHEET . . . . . . . . . . . . . . . . . . . . . . . . . . . . . . . . . . . . . . . . . . . . . . . . . 44

Interventions in the alcohol server setting for preventing injuries (Review)

Copyright @ 2008 The Cochrane Collaboration. Published by John Wiley \& Sons, Ltd 


\title{
Interventions in the alcohol server setting for preventing injuries (Review)
}

\author{
Ker K, Chinnock P
}

This record should be cited as:

Ker K, Chinnock P. Interventions in the alcohol server setting for preventing injuries. Cochrane Database of Systematic Reviews 2006, Issue 2. Art. No.: CD005244. DOI: 10.1002/14651858.CD005244.pub2.

This version first published online: 19 April 2006 in Issue 2, 2006.

Date of most recent substantive amendment: 26 January 2006

\section{A B S T R A C T}

\section{Background}

Injuries are a significant public health burden and alcohol intoxication is recognised as a risk factor for injuries. There is increasing attention on supply-side interventions, which aim to modify the environment and context within which alcohol is supplied and consumed.

\section{Objectives}

To quantify the effectiveness of interventions implemented in the server setting for reducing injuries.

\section{Search strategy}

We searched the Cochrane Injuries Group Specialised Register (September 2004), Cochrane Central Register of Controlled Trials (The Cochrane Library Issue 3, 2004), MEDLINE (January 1966 to September 2004), EMBASE (1980 to 2004, wk 36), other specialised databases and reference lists of articles. We also contacted experts in the field.

\section{Selection criteria}

Randomised controlled trials (RCTs) and non-randomised controlled studies (NRS) of the effectiveness of interventions administered in the server setting which attempted to modify the conditions under which alcohol is served and consumed, to facilitate sensible alcohol consumption and reduce the occurrence of alcohol-related harm.

\section{Data collection and analysis}

Two authors independently screened search results and assessed the full texts of potentially relevant studies for inclusion. Data were extracted and methodological quality was examined. Due to variability in the intervention types investigated, a pooled analysis was not appropriate.

\section{Main results}

Twenty studies met the inclusion criteria. Overall methodological quality was poor. Five studies used an injury outcome measure; only one of these studies was randomised. The studies were grouped into broad categories according to intervention type.

One NRS investigated server training and estimated a reduction of $23 \%$ in single vehicle night-time crashes in the experimental area (controlled for crashes in the control area). Another NRS examined the impact of a drink driving service, and reported a reduction in injury road crashes of $15 \%$ in the experimental area, with no change in the control; no difference was found for fatal crashes. One NRS investigating the impact of a policy intervention, reported that pre-intervention the serious assault rate in the experimental area was $52 \%$ higher than the rate in the control area. After intervention, the serious assault rate in the experimental area was $37 \%$ lower than in the control.

The only RCT targeting the server setting environment with an injury outcome compared toughened glassware (experimental) to annealed glassware (control) on number of bar staff injuries; a greater number of injuries were detected in the experimental group (relative risk 1.72, 95\% CI 1.15 to 2.59). A NRS investigating the impact of a intervention aiming to reduce crime experienced by 
drinking premises; found a lower rate of all crime in the experimental premises (rate ratio 4.6, 95\% CI 1.7 to $12, \mathrm{P}=0.01$ ), no difference was found for injury (rate ratio $1.1 .95 \%$ CI 0.1 to $10, \mathrm{P}=0.093$ ).

The effectiveness of the interventions on patron alcohol consumption is inconclusive. One randomised trial found a statistically significant reduction in observed severe aggression exhibited by patrons. There is some indication of improved server behaviour but it is difficult to predict what effect this might have on injury risk.

\section{Authors' conclusions}

There is no reliable evidence that interventions in the alcohol server setting are effective in reducing injury. Compliance with interventions appears to be a problem; hence mandated interventions may be more likely to show an effect. Randomised controlled trials, with adequate allocation concealment and blinding are required to improve the evidence base. Further well conducted non-randomised trials are also needed, when random allocation is not feasible.

\section{PLAIN LANGUAGE SUMMARY}

Are interventions that are implemented in alcohol server settings (e.g. bars and pubs) effective for preventing injuries?

Injuries are a significant public health burden and alcohol intoxication (i.e. drunkenness) is recognised as a risk factor for injuries; indeed alcohol causes a considerable proportion of all injuries. Alcohol associated injuries are a problem in both high- and low-income countries.

Many interventions to reduce alcohol-related injuries have a demand-side focus and aim to reduce individuals' demand and consequently consumption of alcohol. However, there is increasing attention on supply-side interventions, which attempt to alter the environment and context within which alcohol is supplied and consumed; the aim being to modify the drinking and/or the drinking environment so that potential harm is minimised.

This systematic review was conducted to examine the evidence for the effectiveness of interventions implemented in the alcohol server setting for reducing injuries. The authors of this systematic review examined all studies that compared server settings exposed to an intervention aimed at facilitating sensible alcohol consumption and/or preventing injuries, to server settings not exposed to such an intervention.

The authors found 20 studies; only five of these measured the effect on injury, the remaining 15 measured the effect on behaviour (by the patrons and/or the servers of the alcohol within the premises). The studies investigated a range of interventions involving server training, health promotion initiatives, a drink driving service, a policy intervention and interventions that targeted the server setting environment.

The authors concluded that there is no reliable evidence that interventions in the alcohol server setting are effective in preventing injuries. The effectiveness of the interventions on patron alcohol consumption was found to be inconclusive. There is some indication of improved server behaviour but it is difficult to predict what effect this might have on actual injury risk.

Lack of compliance with interventions seems to be a particular problem; hence mandated interventions or those with associated incentives for compliance, may be more likely to show an effect. The methodology of future evaluations needs to be improved. The focus of research should be broadened to investigate the effectiveness of interventions other than server training, where previous research dominates. When the collection of injury outcome data is not feasible, research is needed to identify the most useful proxy indicators.

\section{B A C K G R O U N D}

\section{Alcohol and injuries as public health problems}

Injuries are a significant global public health burden. During the year 2000, it is estimated that five million people worldwide died from injuries. Globally they account for $9 \%$ of deaths and $12 \%$ of the burden of disease (Peden 2002a). This burden is predicted to worsen; by 2020 it is estimated that deaths from injuries will increase to 8.4 million per year (Murray 1997a). Injuries rank among the leading causes of mortality and burden of disease in all regions, affecting people of all ages and income groups (Peden 2002b).

Injuries can be caused by a number of factors, alcohol being just one. Hence, when considering the public health burden, it is useful to refer to the proportion of all injuries that can be attributed to 
alcohol. The 'attributable fraction' represents the extent to which injury rates would fall if alcohol use was eliminated. By conducting a meta-analysis of epidemiological research (primarily case-control and case-series studies) English et al (English 1996) estimated the alcohol-attributable fractions for a range of disorders. Britton 2001 used the figures from English 1996 and estimated that for England \& Wales in 1996, alcohol was responsible for: approximately 75,000 of premature life years lost, 99 of $210(47 \%)$ deaths from assaults, 66 of $174(38 \%)$ deaths from accidental drowning, 1176 of 3616 (33\%) deaths from accidental falls, 178 of 405 (44\%) deaths from fire-related injuries, 758 of 2948 (26\%) deaths from motor vehicle crashes, and 997 of 3442 (29\%) suicides. However, it should be noted that all estimates of attributable fractions assume causality and can only be as accurate as the studies upon which they are based. The influence of bias, such as confounding, may lead to less accurate estimates and should be considered. Nevertheless, alcohol can be considered to cause a considerable proportion of all injuries.

Evidence that alcohol consumption has some beneficial health effects complicates public health policy in this area. Research has indicated that alcohol, consumed in moderation, is protective against coronary heart disease (CHD) and ischaemic stroke, particularly in the middle-aged and elderly population (Britton 2001). Injuries resulting from alcohol tend to affect drinkers at younger ages, especially in the 15 to 29 years age group, which results in greater years of potential life lost and disability over the proposed life span (WHO 1999). CHD is rare in those younger than 50 years; hence most of the averted deaths are amongst the older ages. Thus, in terms of years of life lost, the adverse effects of drinking may outweigh any protection alcohol offers against CHD (Jernigan 2000).

The problems of alcohol and injury are not confined to developed countries. Indeed, the situation is particularly alarming in lower and middle-income countries, where alcohol consumption is increasing, injury rates are high, and appropriate public health policies have not been implemented (Poznyak 2001). Most of the increase in global alcohol consumption has occurred in developing countries (WHO 2002). In sub-Saharan Africa, where ischaemic heart disease is rare, the protective effects of alcohol are only of marginal public health importance while alcohol is a major cause of death and disability from injury (Murray 1997b).

\section{Prevention approaches: demand versus supply-side interven-} tions

Traditionally, injuries were perceived as random, unavoidable 'accidents', but in recent decades perceptions have altered and injuries are increasingly considered as preventable, non-random events (Peden 2002b).

In the past, many interventions and much of the intervention research focused on individuals, targeting those considered at highest risk of alcohol-related problems. However, it has been suggested that such a focus on 'problem drinkers' is unlikely to result in a sustained decrease in problems at the population level, because the majority of alcohol-related problems are attributable to the substantial number of moderate drinkers who occasionally drink to intoxication (Babor 2003). It is alcohol intoxication (i.e. drunkenness) that is recognised as a strong risk factor for injury, as opposed to long-term exposure to alcohol; thus preventing alcohol intoxication is a potentially effective approach for reducing the harm arising from alcohol (Babor 2003).

Interventions that target all drinkers often have a demand-side focus, aiming to reduce individuals' demands and consequently consumption of alcohol, mainly through educational interventions. An alternative is to take a 'supply-side' approach. The principle of a supply-side approach is to implement interventions that modify the environment within which alcohol is supplied, and the drinking context. Observational research has suggested that the environment of alcohol serving premises can impact on the risk of injury. Specifically relating to violence, factors such as a lack of seating, loud music, overcrowding, lack of available food are considered risk factors (Graham 1997; Homel 1992; Homel 2001; Rehm 2003).

Implementation of interventions in the server setting (e.g. bars, pubs, retailers) has the potential to maximise exposure; every alcohol consumer has contact with the industry in one form or another, while only a small proportion of these consumers come into contact with government services because of their alcohol consumption (Strategy Unit 2004). O’Donnell 1985 estimated that approximately $50 \%$ of alcohol-related traffic crashes involve the prior consumption of alcohol on licensed premises, and a strong association between public violence and drinking on licensed premises is documented (Stockwell 2001). Hence, when such risky consumption occurs within a highly regulatable system of servers, it makes them a logical focus for prevention efforts.

Efforts applied to the server setting imply a level of acceptance that alcohol consumption will occur but aim to modify the drinking and/or the drinking environment so that potential harm is prevented. Interventions within server settings can range from the way alcohol is packaged, promoted and sold, to the overall management and policy of the establishment within which it is consumed. Such interventions include server training, use of alternatives to standard drinking glassware (for example, toughened glass, plastic containers), discontinuation of alcoholic drink promotions (for example, 'happy hours'), using server settings as sites for health promotion initiatives amongst others, which may be implemented individually or in combination.

\section{Need for a systematic review}

Reviews of research are essential tools for health care workers, researchers, consumers and policy-makers who want to keep up to date with evidence in their field. Systematic reviews enable a more objective appraisal of the evidence than traditional narrative reviews, and are important in demonstrating areas where the available evidence is insufficient and where further good quality trials are required (Egger 2001). 
It is important that the effectiveness of interventions in the server setting is evaluated to aid policy decision-making and priority setting. Graham 2000 published a comprehensive narrative literature review of preventive approaches for on-premise drinking, and Shults 2001 conducted a systematic review to examine the effectiveness of server education specifically for preventing drink driving. However, no other systematic review attempting to quantify the effectiveness of all interventions delivered in the server setting on reducing all forms of injury has been identified. The purpose of this systematic review is to critically review the current evidence for the use of interventions delivered in the server setting for preventing injury.

\section{O B J E C T IVE S}

To quantify the effectiveness of interventions in the alcohol server setting for reducing injuries.

\section{CRITERIA FOR CONSIDERING STUDIES FOR THIS REVIEW}

\section{Types of studies}

The following randomised and non-randomised study designs were eligible.

\section{Randomised controlled trials}

Participants are randomly allocated to intervention or control groups and followed up over time to assess any differences in outcomes.

\section{Cluster randomised controlled trials}

Groups of participants are randomly allocated to intervention or control groups and followed up over time to assess any differences in outcomes.

\section{Non-randomised trials}

The investigator has control over the allocation of participants to groups but does not use randomisation.

\section{Controlled before-and-after studies}

A follow-up study of participants who have received an intervention and those who have not, measuring the outcome variable at both baseline and after the intervention period, comparing either final values if the groups are comparable at baseline, or change scores.

(Definitions adapted from those cited in Deeks 2003)

Despite being more prone to bias than studies using random allocation, we decided to include non-randomised designs in light of the practical constraints of conducting RCTs in this area.

\section{Types of participants}

- Workers in licensed alcohol serving premises (e.g. bar staff, shop workers)

- Owners and managers of alcohol serving premises

- Patrons in licensed alcohol serving premises

- Licensed alcohol serving outlets (e.g. retailers, pubs, bars, clubs, restaurants) including 'off-licences' (i.e. premises which do not have a licence for on-premise consumption, but sell alcohol for off-premise consumption).

- Areas of multiple licensed alcohol serving outlets (e.g. towns)

\section{Types of intervention}

Eligible interventions were those administered in the server setting which attempted to modify the conditions under which alcohol was served and consumed, to facilitate sensible alcohol consumption and reduce the occurrence of alcohol-related harm. Studies of server interventions that were administered in a programme involving other ineligible (that is, not in the server setting) interventions were considered if outcomes attributed to the eligible serverintervention component could be distinguished.

Legislative interventions such as server liability, licensing/opening hours, and advertising restrictions were not eligible.

\section{Types of outcome measures}

Primary measures

- Fatal injuries

- Non-fatal injuries

(Data on all alcohol-related injuries was considered, irrespective of whether the injured individual had consumed alcohol or not.)

\section{Secondary measures}

- Behaviour change (e.g. change in amount of alcohol consumed)

- Knowledge change

\section{SEARCH METHODS FOR IDENTIFICATIONOF STUDIES}

See: Cochrane Injuries Group methods used in reviews.

We searched the following electronic databases;

- Cochrane Injuries Group’s Specialised Register (September 2004)

- Cochrane Central Register of Controlled Trials (CENTRAL) (The Cochrane Library Issue 3, 2004)

- MEDLINE (January 1966 to September 2004)

- EMBASE (1980 to 2004, wk 36)

- ERIC (1966 to September 2004) 
- ETOH (January 2005)

- National Research Register (issue 3/2004)

- PsycINFO (September 2004)

- Science (and Social Science) citation index (September 2004)

- SIGLE (1980 to $2004 / 06$ )

- SPECTR (September 2004)

- TRANSPORT (1988-2004/06)

- Zetoc (1993 to September 2004)

The full search strategies are presented in the additional tables (Table 01; Table 02; Table 03; Table 04; Table 05; Table 06; Table 07).

We searched the internet search, checked the reference lists of relevant studies and, where possible, contacted the first author of each included study to identify further potentially eligible articles.

The searches were not restricted by publication status, date, or language.

\section{METHODS OF THE REVIEW}

\section{Trial identification and selection}

We independently examined titles, abstracts, and keywords of citations from electronic databases for eligibility. We obtained the full text of all relevant records and independently assessed whether each met the pre-defined inclusion criteria. We resolved disagreement by discussion.

\section{Data extraction}

We extracted data from each eligible study using a standard form that we had developed specifically for this review. We extracted data on the following:

- study date and setting;

- sample size;

- study design;

- method of allocation;

- blinding of outcome assessment;

- characteristics of intervention and control groups;

- characteristics of intervention;

- the outcomes evaluated;

- results;

- duration of follow up;

- loss to follow up;
- intention to treat.

Where necessary and possible, we sought additional information from researchers involved in the original studies.

We were not blinded to the names of the authors, institutions, journal of publication, or results of the trials, because evidence for the value of this is inconclusive (Berlin 1997).

Assessment of methodological quality

The Health Technology Assessment report, 'Evaluating nonrandomised intervention studies' (Deeks 2003), contains a systematic review of quality assessment tools used for nonrandomised studies and identifies six judged to be potentially useful for use in systematic reviews. For the present systematic review, from these six, we selected a tool developed by the Effective Public Health Practice Project (Thomas 2003) to assess methodological quality of all the study designs. We opted for Thomas 2003 as we anticipated it to be the most suitable for the type of studies that we anticipated to identify, hence requiring the least modification. Deeks classified this tool as using a 'mixed criteria' approach. It involves specific factual questions in regard to study design alongside judgements as to the degree of bias present in the study; such an approach may 'prove to be the most useful for systematic reviews' (Deeks 2003). The tool by Thomas primarily considers study validity with the following eight main components:

- selection bias;

- study design and allocation bias;

- confounders;

- blinding;

- data collection methods;

- withdrawals and dropouts;

- intervention integrity;

- analysis.

Data analysis

On inspection of the eligible studies, it was clear that there was a high degree of heterogeneity in terms of participants, interventions and outcomes (that is, clinical heterogeneity) which meant that a pooled analysis would not be appropriate. Therefore data were reviewed qualitatively for each study, presenting effect estimates, precision and statistical significance as reported. We calculated odds ratios (OR) and weighted mean difference (WMD) for the RCTs where possible.

\section{DESCRIPTIONOF STUDIES}

The combined search strategy identified approximately 3,550 studies, of which 62 were deemed to be potentially relevant based 
on title or abstract. After a full text review, 20 studies were judged to meet the inclusion criteria.

The studies had been conducted in five countries; five in Australia, ten in the USA, two in Canada, two in Sweden and one in the UK, published over a 17 year period (1987 to 2004).

Six studies were randomised, nine were non-randomised and five used a controlled before-and-after design. Twelve studies used individual premises as the unit of allocation; one trial used individual servers and the remaining seven used areas containing multiple serving establishments (e.g. towns).

Fourteen studies compared a responsible server training intervention with no training. Two studies investigated the effectiveness of delivering health promotion information in serving establishments. Two studies examined interventions that targeted the server setting environment. One study focused on the management policies of serving premises, and one study investigated the effectiveness of a driving service for intoxicated patrons.

Five studies used an injury outcome. Fourteen studies collected data on behaviour (of servers and/or of patrons) and six studies collected data on changes in knowledge.

A more detailed description of the individual studies is presented in the 'Characteristics of included studies' table.

\section{METHODOLOGICAL QUALITY}

The quality assessment tool developed by the Effective Public Health Practice Project (Thomas 2003) was selected, at the protocol stage. It was decided not to use the tool to derive an overall score of each study; Higgins et al discusses how the relationship between a quality score and the extent to which a study is free from bias is not clear (Higgins 2005). Also, deriving one summary score by adding the scores for each item is not supported by the evidence, thus it is suggested that it is preferable to fully report how each trial performed on each criterion. Therefore, a modified framework of the Thomas 2003 quality tool has been used to describe each of the included studies against the following criteria as available from the report;

- Allocation bias (for example, was allocation to the experimental and control groups random and adequately concealed?)

- Confounders (for example, did the groups under study differ in terms of distribution of potential confounders?)

- Blinding (for example, were the outcome assessors blind to the allocation status of the participants?)

- Data collection methods (for example, were outcome data collected through self-report methods or more objective methods such as researcher observation or extracted from official records?)
- Withdrawals and dropouts (for example, how many participants failed to complete the study and/or were lost to follow-up?)

- Intervention compliance (for example, what proportion of participants received the allocation intervention?)

- Duration of follow-up (for example, how long was/were the data collection period(s)?)

Below is a summary of the quality of the trials against these criteria, however full details of each study's rating against each criterion are presented in the additional tables.

Allocation bias (Table 08)

In intervention studies, allocation should ideally be random and concealed. Allocation that is not random is likely to lead to unbalanced prognostic factors between the experimental and control groups, which will result in a biased estimate of the intervention effect. Seven studies reported using random allocation; the method used was available for three; drawing lots was used in two (Graham 2004; Johnsson 2003), and a table of random numbers was used in one (McLean 1994). All of these methods are of inadequate concealment.

One study (Casteel 2004) allocated the bars who agreed to participate in the study to the experimental group and those that refused to the control group. Two studies (Boots 1995; Felson 1997) allocated the intervention to an area previously identified as having a particularly high rate of alcohol-related problems; regression-tothe-mean should be considered in such instances and is described further in the 'Discussion' section.

Comparability of experimental and control groups at baseline (Table 09)

Baseline differences in alcohol-related problems and/or average alcohol consumption between the experimental and control groups were reported in three studies (Boots 1995; Casteel 2004; Felson 1997). Nine studies attempted to match participants prior to allocation (Gliksman 1993; Graham 2004; Howard-Pitney 1991; Krass 1994; Lang 1998; McKnight 1991; Saltz 1987; Saltz 1997; Toomey 2001), although the number and type of factors matched for varied with each study. Two studies reported that the experimental and control groups had similar characteristics (Buka 1999; Lang 1998). The remaining six studies did not report the presence (or absence) of baseline differences between the groups (Holder 1994; Johnsson 2003; McLean 1994; Russ 1987; Wallin 2002; Warburton 2000).

\section{Blinding (Table 10)}

To minimise observer bias, outcome assessors should ideally be blinded to the allocation status of participants, as they may be biased towards one group (consciously or not). Blinding of outcome assessment was used in 11 studies that used observers/interviewers to gather outcome data. The randomised trial of toughened glassware (Warburton 2000) also blinded the participants to their own allocation status. Such a double-blind design is not feasible in the 
other studies, due to the nature of the interventions under investigation; for example, participants cannot be blind to whether they received training or not.

Injury data (traffic crashes and violence) was collected from official records in four trials.

\section{Data collection methods (Table 11)}

Methods by which outcome data are collected may be associated with their own biases. For example, self-reported measures of behaviour are likely to be more prone to bias than observed behaviour.

In the six studies with a knowledge outcome, five of these measured this in the trained servers only. All trials used a self-completed test or questionnaire method. Response rates were high in the studies measuring knowledge immediately after the training, however were lower in those with a longer follow-up.

Behaviour was measured in two studies (Boots 1995; Buka 1999) using self-reported data as the source of outcome data. Response rate to questionnaires tended to be low. Data on behaviour was gathered through observations by investigators in eight studies. Three (Johnsson 2003; Krass 1994; McLean 1994) out of the four studies undertaking patron interviews used a breath test to assess intoxication whilst one (Saltz 1987) collected self-reported data on alcohol consumption. With the exception of Johnsson 2003, which achieved an extremely high response rate for patron interview (>95\%), the remaining studies response rates were lower (range of 40 to $65 \%$ ).

All but one of the studies gathering injury outcome data used official records as the source, the exception being Warburton 2000 which used a self-complete questionnaire.

\section{Withdrawals and dropouts (Table 12)}

Withdrawals and dropouts need to be minimised in any intervention study. Participants choosing to withdraw from the study are likely to be those with the worst prognosis. It is also important that participants who do not receive or complete their assigned intervention, remain in the analysis (that is, analysis is on an intention-to-treat basis).

Seven studies (Boots 1995; Buka 1999; Felson 1997; Holder 1994; Lacey 2000; Saltz 1997; Wallin 2002) allocated the intervention to areas of alcohol serving premises, and received a 'n/a' rating for this criterion. As the design was directed as a geographical area the percentage of participants completing, withdrawing or dropping out is not applicable.

Seven studies (Casteel 2004; Gliksman 1993; Howard-Pitney 1991; Johnsson 2003; McKnight 1991; Russ 1987; Saltz 1987) using individual bar/premises as the unit of allocation, did not report any withdrawals, drop-outs or loss to follow-up.

Three studies (Krass 1994; Lang 1998; McLean 1994) reported bars refusing to participate in the patron surveys.
Three studies (Graham 2004; Toomey 2001; Warburton 2000) reported bars withdrawing and/or lost to follow-up; none of these studies presented outcome data for the affected bars.

\section{Intervention integrity and compliance (Table 13)}

Seven studies examining server training reported the number of participants trained as a proportion of total servers; two reported training all staff, one trained $84 \%$ while the remaining four trained 50 to $60 \%$ of staff. One of the trials was of a mandated training policy, so it is assumed that compliance was high.

The two studies examining health promotion interventions both reported that the extent of compliance with the intervention varied between premises for example, varying from displaying the information to actively distributing it, no further details are reported.

The Warburton 2000 study involved replacing the bars' whole glassware supply; hence it is assumed compliance was high. The Casteel 2004 study involved making recommendations to managers to implement environmental changes to the bar, again it was reported that compliance was variable.

Follow-up duration (Table 14)

In the studies assessing the change in knowledge (Boots 1995; Gliksman 1993; Howard-Pitney 1991; Krass 1994; Lang 1998; McKnight 1991), measurements were made immediately before and after training in two studies, three months after in one with the remaining three not specifying length of data collection periods in the report.

The timing of post observations of server behaviour to pseudopatrons occurred within six months of administration of the intervention, with the exception of one (Wallin 2002) in which observations were made three years after.

The timings of the patron interviews/surveys ranged from less than one week to three months after intervention implementation.

The length of data collection periods of injury data in the controlled before-and-after studies ranged from nine months to 11 years before and from three months to 15 years after. The Warburton 2000 randomised trial collected injury data for six months after.

\section{RES U L T S}

Due to variability in the intervention types investigated by the included studies, the results have been reviewed qualitatively. The interventions have been grouped into five broad categories; server training, health promotion initiatives, drink driving service, interventions targeting the server setting environment, and policy interventions. With the exception of Graham 2004, studies in the server training category were investigating a sufficiently similar intervention to enable the studies to be presented together, with the results grouped by outcome. The focus of the training in Graham 2004 differed from the others thus has been reported separately. 
The results of the remaining studies in the other categories have been presented by study due to the variability of the interventions under investigation.

\section{Server training}

Fourteen studies investigated the effectiveness of server training; duration of the training interventions ranged from one to two hours to two days. All but one study involved training focusing on the responsible service of alcohol. Common training themes included raising awareness of alcohol service laws, recognition of early signs of alcohol intoxication, and tactics for dealing with intoxicated customers. Five of these reported a specific focus and/or specific training for the managers/owners in responsible alcohol service policies. In Graham 2004, the training was not targeted at responsible service, but on the prevention and management of aggression in bars.

\section{Injury (Table 15) \\ Randomised controlled trials}

None identified.

\section{Non-randomised studies}

One study (Holder 1994) measured injury as an outcome. Holder 1994 investigated the impact of a state-wide mandated server training policy and estimated a continued reduction in the number of single vehicle night time (SVN) crashes; after controlling for drink driving related policy changes and the trend of crashes in the control area, it was estimated that the intervention lead to a reduction of $4 \%$ after six months, $11 \%$ after 12 months, $18 \%$ after 24 months, reaching $23 \%$ after 36 months.

\section{Patron behaviour (Table 16)}

Patron behaviour was measured in terms of alcohol consumption in four studies (Johnsson 2003; Krass 1994; Lang 1998; Saltz 1987); three used breath tests to measure BAC, while one (Saltz 1987) used self-reported alcohol consumption.

\section{Randomised controlled trials}

In the randomised study by Johnsson 2003 the post-intervention mean BAC levels were lower in the experimental bars $(0.082 \%)$ than the control bars $(0.087)$ (WMD $=-0.01$ (95\% CI -0.02 to 0.00$)$. The study authors compared the change in BAC from pre to post intervention for both groups; the mean BAC in the experimental bars reduced to a greater extent than in the control bars, mean difference $=-0.011 \%(95 \%$ CI 0.022 to 0.000$)$. The odds ratio indicates a modest effect on the percentage of patrons with a BAC $>0.1$ (OR 0.92, 95\% CI 0.67 to 1.26$)$, although this is compatible with the play of chance.

The randomised trial by Krass 1994 reported that a statistically significant difference was not found between experimental and control bars in mean patron BAC or total consumption, with values increasing for both outcomes in both groups. The mean BAC in the post intervention period was $0.069 \mathrm{gm} \%(95 \% \mathrm{CI} 0.058$ to 0.078 ) in the experimental and $0.058 \mathrm{gm} \%(95 \% \mathrm{CI} 0.050$ to $0.066)$ in the control. The percentage of patrons with a BAC >
0.10 in the after period was $27 \%$ in the experimental group and $20 \%$ the control; no confidence intervals or significance test were reported.

\section{Non-randomised studies}

In Lang 1998, the change in percentage of patrons with a BAC $>0.15$ over the study period declined for both groups (by $12.1 \%$ in the experimental, by $6.4 \%$ in the control); the reductions were not found to be significantly different $(\mathrm{P}=0.389)$. A positive intervention effect was found for the change in the percentage of patrons with a BAC $>0.08$, with the percentage decline significantly greater in experimental bars $(-25.1 \%)$ than the control ($10.8 \%), \mathrm{P}<0.029$. Lang 1998 also measured subsequent drink driving offences, but detected too few offences to evaluate and no data were presented.

Saltz 1987 compared two Navy clubs, one of which received server training. Self-reported data indicated no effect on overall alcohol consumption or rate of consumption of alcohol, $\mathrm{P}>0.05$. However, a positive intervention effect on the risk of having a $\mathrm{BAC}>$ $0.10 \%$ (as estimated from the number of drinks consumed) was found, $\mathrm{P}<0.05$.

\section{Server behaviour (Table 16)}

\section{Randomised controlled trials}

Gliksman 1993 used a behaviour score based on observations of six scenarios (the higher the score the more desirable the behaviour). Estimates (read from a graph) showed an increase of score in the experimental sites $(+6.5)$ and a slight decrease $(-0.1)$ in the control. The difference in score change was found to be statistically significant, $\mathrm{P}<0.01$.

\section{Non-randomised studies}

McKnight 1991 calculated mean scores of server intervention for each group (the higher the score the more desirable). The score in the experimental sites increased by 0.15 and remained unchanged in the control sites, between the pre and post periods. Significance test indicates a significant difference, $\mathrm{P}=0.01$. McKnight 1991 also applied an intervention score to observed server behaviour to 'real' intoxicated patrons; the level increased significantly in the experimental bars $(\mathrm{P}=0.04)$ but not in the control bars $(\mathrm{P}=0.35)$ pre to post intervention.

Howard-Pitney 1991 calculated the mean number of interventions made by servers for eight different responsible interventions. The overall mean for all eight interventions (the higher the mean value the more desirable the behaviour) was 0.95 for experimental and 1.26 for the control bars. Neither confidence intervals or P values were presented for these estimates; however, the authors reported that 'no differences were observed between treatment and control servers on any intervention or on a sum average of eight possible interventions'.

Saltz 1997 calculated a behaviour score (ranging of low [=bad] of 2 to $+2[$ =good]). In the North Californian communities the score 
increased by 0.04 in the experimental, and by 0.34 in the control. In the South Californian communities the score increased by 0.01 in the experimental community and by 0.01 in the control. In the South Carolina communities the score reduced by 0.1 in the experimental and increased by 0.14 in the control. The authors report that 'no statistical difference was found', no further information was presented.

The study by Russ 1987 recorded the number of observed responsible interventions made by the servers, and found that the trained servers had a higher frequency of responsible interventions than the untrained servers $(\mathrm{P}<0.05)$. The exit BAC of the pseudopatrons was also measured, post-test only; for the experimental group, average exit $\mathrm{BAC}=0.103(+/-0.033)$ and for control $=$ 0.059 (+/-0.019), this was reported as significant, $\mathrm{P}<0.01$. Mean difference in the exit BAC of pseudo-patrons served by experimental versus control servers $=0.044$ (95\% CI 0.022 to 0.066 ).

Three studies (Lang 1998; Toomey 2001; Wallin 2002) compared the change in the number of service refusals to pseudo-intoxicated patrons; neither study found a significant difference between the experimental and control groups.

In Lang 1998 pseudo-patrons were refused service, in 1/11 and $3 / 14$ visits in the experimental group in the pre and post period, respectively. In the control group, $1 / 14$ visits were refused in both the pre and post intervention period. The authors report that no further analyses were undertaken of this data, due to the small numbers. In the study by Toomey 2001, refusal of service to pseudointoxicated patrons decreased from 83.1 to $80.3 \%$ in the experimental and from 63.0 to $54.8 \%$ in the control, the difference between the changes was not found to be significant, $\mathrm{P}=0.81$. Wallin 2002 found that, three years post intervention the refusal rates to pseudo-intoxicated patrons was $55 \%$ in the experimental premises that had received training, $48 \%$ in the experimental sites yet to have received training and $38 \%$ in the control area. The authors reported that the differences were not significant, but exact results of the significance test were not reported.

The study by Toomey 2001 also measured server behaviour in terms of the number of the number of successful purchase attempts by pseudo-intoxicated patrons (that is, the lower the number of successful purchases, the more desirable the behaviour). Purchase attempts reduced from $68.4 \%$ to $40.0 \%$ and increased from $70.1 \%$ to $72.9 \%$ over the study period in the experimental and control sites, respectively. The relative decline was reported as not being statistically significant, $\mathrm{P}=0.81$.

Three studies (Buka 1999; Lang 1998; Saltz 1997) measured selfreported server behaviour, none of which found a statistically significant difference between experimental and control.

Buka 1999 measured self-reported server behaviour according to a Desired Server Behaviour Index (scale from 1 to 5, the higher the score the more desirable the behaviour) in the experimental and two control communities. Mean DSBI (+/-SD) was $3.59(+/-$
$0.74)$ in the experimental community, $3.59(+/-0.61)$ and 3.24 $(+/-0.65)$ in control $\mathrm{A}$ and $\mathrm{B}$ communities respectively, $\mathrm{P}=0.06$.

Lang 1998 measured server behaviour by calculation of a score, based on reported adoption of responsible service policies over the pre to post period, each bar was rated against 11 dimensions of responsible service. Average ratings of experimental sites increased in a positive direction for 4/11 dimensions, with the rest unchanged. In the control sites there was one positive, two negative and eight unchanged dimensions in the control sites. The authors report the difference not to be statistically significant but the exact results of significance test were not presented.

Saltz 1997 measured the percentage of premises reporting as having a policy of refusing service to intoxicated patrons. In the North Californian communities the percentage reporting 'yes' increased by $16 \%$ in the experimental, and by $2 \%$ in the control. In the South Californian communities the score increased by $9 \%$ in the experimental community and by $2 \%$ in the control. In the South Carolinian communities the score reduced by $1 \%$ in the experimental and decreased by $2 \%$ in the control. The authors report that 'no statistical difference was found', but no further information was presented.

\section{Knowledge (Table 17)}

Randomised controlled trials

Gliksman 1993 and Krass 1994 reported a statistically significant improvement in knowledge after training $(\mathrm{P}<0.05)$. This outcome was measured in the trained servers only.

\section{Non-randomised studies}

Two studies (Howard-Pitney 1991; Lang 1998) measured change in knowledge in the trained servers. Both reported a statistically significant improvement in knowledge after training $(\mathrm{P}<0.05)$. This outcome was measured in the trained servers only.

\section{Server training to reduce aggression}

The randomised trial by Graham 2004 measured the effect of a 'safer bars' training programme on reducing observed aggression exhibited by patrons and staff, the primary outcome being the average number of incidents of severe or moderate aggression per observation.

A significant positive intervention effect $(\mathrm{P}<0.001)$ was found for severe physical aggression exhibited by patrons (consistent rating by all raters; definite intent); with average number of incidents falling by 0.018 in the experimental and increasing by 0.053 in the control. A positive intervention effect was also observed when examining all severe aggression plus consistent rating of moderate physical (with or without verbal aggression; definite intent), with the average number of incidents decreasing by 0.033 in experimental and increasing by 0.051 in the control over the trial period, however this did not reach statistical significance $(\mathrm{P}=0.071)$.

The number of incidents of severe physical aggression exhibited by staff (consistent rating by all raters; definite intent); was too 
low to enable analysis. Analysis of all severe plus consistent rating of moderate physical (with or without verbal aggression; definite intent), indicated an increase in average number of incidents by 0.027 in the experimental and an increase of 0.039 in the control bars $(\mathrm{P}=0.243)$, over the trial period.

\section{Health promotion initiatives (Table 18) \\ Injury}

No studies identified.

\section{Patron behaviour \\ Randomised controlled trials}

One trial was found. McLean 1994 investigated the effectiveness of the distribution and display of sensible drinking information in bars on the alcohol consumption of patrons. No statistically significant difference was found between the control and experimental bars in any of the measures of alcohol consumption used with the exception of the self-reported data. After the intervention the median $\mathrm{BAC}(\mathrm{mg} \%)$ was 0.030 in both the experimental and control groups $(\mathrm{P}=0.415)$; the percentage of patrons with a $\mathrm{BAC}$ $>0.10$ was $17.5 \%$ and $20.0 \%$ in the experimental and control groups, respectively $(\mathrm{P}=0.509)$. The odds ratio for the percentage of patrons with a BAC $>0.1$, indicated a modest intervention effect (OR $0.85,95 \% 0.56$ to 1.29 ; $\mathrm{n}=18$ bars), although this is compatible with the play of chance. The percentage of patrons with a BAC $>0.15$ was $7.5 \%$ and $7.8 \%$ in the experimental and control groups, respectively ( $\mathrm{P}=1.000)$; OR 0.96 (95\% CI 0.52 to 0.77$)$. Self-reported alcohol consumption was significantly less in the experimental group $(38 \mathrm{~g})$ than the control $(47 \mathrm{~g})$ with $\mathrm{P}=$ 0.01 ; the percentage of patrons with a $\mathrm{BAC}>0.05 \%$ who intended to drive was $6.8 \%$ in experimental and $7.8 \%$ in control group ( $\mathrm{P}$ $=0.635$ ).

\section{Non-randomised studies}

Boots 1995 investigated the effectiveness of the distribution cards containing 'safe-partying' tips through liquor stores. Self-reported data on the behaviour of drinkers were collected. Comparing pre and post intervention responses, no difference was found in the number of drinkers adhering to the tips (providing food, $\mathrm{P}=$ 0.4675 ; providing alternative drinks, $\mathrm{P}=0.844$; reducing service to intoxication, $\mathrm{P}=0.1194$; providing alternative transport, $\mathrm{P}=$ 0.1862). For the control town, no data is reported, however the authors state that there was no significant pre to post difference. Drinkers' knowledge of the tips promoted by the intervention was only measured in the experimental area; it was reported that there was no significant community-wide change in safe-partying knowledge resulting from the campaign, $\mathrm{P}=0.813$.

Drink driving service (Table 19)

Injury

Randomised controlled trials

None identified.
Lacey 2000 investigated the effectiveness of a free driving home service for intoxicated drinkers. Injury crashes reduced by $15 \%$ in the experimental area after implementation of the programme $(t$ $=-2.61$, reported as 'highly significant'), the authors report that there was no reduction in the control areas. A before-and-after analysis of the ratio of the experimental area's fatal crashes to the control's fatal crashes, indicated that the ratio reduced from 0.78 to 0.60 , this was reported as not being statistically significant $(\mathrm{P}=$ 0.29 ).

\section{Behaviour}

None identified.

\section{Knowledge}

None identified.

Interventions targeting the server setting environment (Table 20)

\section{Injury}

Randomised controlled trials

Warburton 2000 was the only included study to be randomised and use an injury outcome. The study compared the effectiveness of two types of drinking glassware; toughened glassware (experimental) and annealed glassware (control) in reducing bar-staff injuries. The results indicated that the experimental glass caused more injury than the control. Seventy-two and 43 staff experienced glass injuries in the experimental and control bars, respectively. The ratio of number of staff injured in the experimental group to the number in the control $=1.72(95 \%$ CI 1.15 to 2.59$)(-70 \%$ greater risk of injury in experimental group). The relative risk adjusted for people at risk $=1.48(95 \%$ CI 1.02 to 2.15$)(-50 \%$ greater risk of injury in experimental group). The relative risk adjusted for hours worked $=1.57(95 \%$ CI 1.08 to 2.29$)(-60 \%$ greater risk of injury in experimental group). All P values were < 0.05 .

\section{Non-randomised studies}

Casteel 2004 investigated an intervention aimed at reducing crime experienced by the drinking establishment and used a number of injury measures as outcomes, with a statistically significant intervention effect detected for two; all crime and number of police reports. Comparing the control versus experimental stores, rate ratios (RR) (adjusted for reported district crime) and 95\% CI and $P$ values were reported; for robbery RR 5.4 (95\% CI 0.7 to 43 ) $\mathrm{P}=0.11$; for assault RR 3.4 (95\% CI 0.7 to 18$) \mathrm{P}=0.13$; for shoplifting RR 5.6 (95\% CI 0.9 to 36) $\mathrm{P}=0.07$; for all crime $\mathrm{RR}$ 4.6 (95\% CI 1.7 to 12$) \mathrm{P}=0.01$; for injury RR 1.1 (95\% CI 0.1 to 10$) \mathrm{P}=0.93$; and for police reports RR 2.7 (95\% CI 1.3 to 5.4$)$ $\mathrm{P}=0.01$.

\section{Behaviour}

None identified.

Knowledge

None identified.

Server setting policy intervention (Table 21) 


\section{Injury}

Randomised controlled trials

None identified

Non-randomised studies

One study, Felson 1997, used a controlled before-and-after design to investigate the impact on serious assault rate, after the introduction of a policy aimed at minimising the movement of drinkers between different bars and their alcohol consumption. The authors reported that before the policy intervention, the serious assault rate in the experimental area was $52 \%$ higher than the rate in the control area. After the intervention, the serious assault rate in the experimental area was $37 \%$ lower than in the control.

\section{Behaviour}

None identified.

\section{Knowledge}

None identified.

\section{I S C U S S I O N}

\section{Principal findings}

There is no reliable evidence that interventions in the alcohol server setting are effective in preventing injuries. Only one randomised trial with an injury outcome was identified and this did not detect a beneficial intervention effect. Three randomised control trials measured patron alcohol consumption, none of which found a confident estimate of effect. One randomised trial found a statistically significant reduction in observed severe aggression exhibited by patrons. There is some indication of an improvement in server behaviour, however, the extent to which this translates into a reduction in injury risk is unknown, and thus interpretation of this outcome is of limited value.

\section{Strengths and weaknesses of this systematic review}

This systematic review addresses a focused research question using predefined inclusion criteria and methodology to select and appraise eligible studies.

As with all systematic reviews, the possibility of publication bias should be considered as a potential threat to validity. Identification of research for systematic reviews of public health interventions tends to require more complex searching than for reviews of medical interventions. The multi-disciplinary nature of the research means that it is more widely scattered, with much published in the grey literature (Jackson 2005a). In recognition of this, the search strategy for this systematic review involved searching multiple electronic databases from a range of disciplines (including two specifically of grey literature), checking of reference lists and contact with experts in the field, to identify all potentially eligible studies, published and unpublished. With such a comprehensive search strategy, the likelihood of having missed an important, relevant study is remote, thus the influence of publication bias on the findings of this systematic review can be discounted with reasonable confidence.

The included studies often used a number of outcome measures to examine intervention effectiveness; it was not possible for us to anticipate all of these when defining the inclusion criteria at the protocol stage. Therefore, for a small number of studies, we selected to report only the measures which we judge to be the most reliable and meaningful in contributing to the objectives of the review. Although these decisions were not made in reference to the results data, they are post hoc decisions and thus a potential weakness of this review.

The findings of this systematic review are limited by the overall poor methodological quality of the included studies; poorly designed and executed studies are susceptible to bias and can lead to either an over or under estimate of effect.

Several studies were conducted over a decade ago, so their relevance and generalisability to the present situation is questionable. An additional limitation is that no studies conducted in low and middle income countries were identified.

\section{Strength and weaknesses of the included studies}

The validity of the inferences based on a systematic review is dependent on the quality of the included studies. Overall, the methodological quality of the studies included in this review was judged to be weak.

Only six studies used random allocation, and none of these were found to have adequate allocation concealment. Three of these six studies used a cluster design and randomly allocated a very small number of clusters (Buka 1999; Gliksman 1993; Krass 1994). The benefits of randomisation are unlikely to be achieved with very small numbers. These studies have been classified as randomised trials in this systematic review however, they are likely to be as susceptible to allocation bias as the non-randomised trials.

Attempts were made in nine of the non-randomised designs to minimise confounding through matching of the experimental and control groups, however residual confounding remains a problem.

Ineffective and poorly concealed randomisation in the included studies, means confounding and bias are likely to have influenced the results.

Two studies allocated the intervention to an area previously identified as having a particularly high rate of alcohol-related problems. With such an approach, regression-to-the-mean should be considered. Regression-to-the-mean describes the tendency for an abnormally high (or low) number of events (e.g. injuries) to return to values closer to the long term mean. Any observed abnormally high (or low) number of events is thus a result of random fluctuation. It is a particular threat to controlled-before-and-after studies and has important implications when the study interest is a change in outcome. In such cases an apparent intervention effect may actually be a result of the number of events returning to 
the average rate after a random fluctuation. Consequently, these studies should be interpreted with caution.

Blind outcome assessment was widely used in the included studies. It was reported as being used in 11 studies during the collection of behaviour data (important when collecting data on such a subjective outcome). Additionally, the studies measuring injury outcome extracted data from official records (e.g. crash data from government statistics, crime data from police records). When using data from such external, objective sources it is reasonable to assume that outcome assessment is blind.

Questionnaires and interviews were often used to examine behaviour; the response rates were low in a number of studies. This is a source of potential bias as the non-responders are likely to have the worst prognosis or be at most risk. Such a bias leads to an overestimation of an intervention effect. A number of studies attempted to minimise this bias in the patron interviews, by judging the intoxication level of non-responders. Similarly, participants who withdraw from the study or are lost to follow-up are likely to have a poorer prognosis. However, details of such withdrawals and drop-outs were often not reported; of the few studies that did, it seemed that analysis was not on an intention-to-treat basis, nor was outcome data for such non-participants presented. Cautious interpretation of such studies is needed, as it is likely that their findings over-estimate any intervention effect.

Intervention compliance was also a problem for many of the studies. In the server training studies, the number of servers actually receiving training in the experimental groups was relatively low, often 50 to $60 \%$. Hence, follow-up observations of server behaviour had a good chance of being based on a number of untrained servers. In the health promotion studies, compliance was reported as 'variable'. Such a low or variable compliance is a problem for the assessment of intervention efficacy, but does indicate the effectiveness of such interventions, which is arguably of greater interest to public health intervention research.

It is difficult to quantify a sufficient length for a data collection period, but it should be long enough to account for short-term fluctuations to provide a reliable estimate of outcome. Due to the relatively short length of follow-up in most studies it is difficult to be confident that a change in outcome is a result of random fluctuation or if any real intervention effect lessens (or increases) over time.

A number of the included studies used a cluster design. A problem posed by cluster data arises from the fact that individuals within a cluster tend to be more similar to each other than to other members of other clusters. Failure to account for this can cause a type of' unit of analysis error', which results in the P-values being too small and the confidence intervals too narrow (Wears 2002), and can spuriously overestimate the significance of difference (Alderson 2002). Eight studies reported using appropriate statistical techniques to adjust for this cluster error in their analyses.
Of the variety of interventions that have the potential to be implemented in the server setting, much of the existing literature and intervention research focuses on just one: server training. Such an approach places the emphasis on the supply-side of alcohol consumption and aims to enable servers to facilitate responsible drinking in their patrons. The approach assumes that an improvement in knowledge leads to an improvement in behaviour, which in turn will reduce the occurrence of injury. However, the appropriateness of this assumption might be questioned; behaviour is a complex concept and subject to multiple influences, knowledge being just one. For example, it is recognised that educational interventions are not effective in reducing alcohol consumption (Hope 2004), hence to assume that such an approach can change the behaviour of servers may be inappropriate.

The required large sample size is likely to be a main reason for the lack of injury outcome data in the included studies, with proxy measures such as behaviour used instead. However, it is unclear how observed behaviour is related to the occurrence of injury. Even if a causal relationship between behaviour and injury is assumed, there is no reliable effect estimates which would enable the prediction of the extent to which a given behaviour change reduces the rate of injury. For example, two of the studies of server training used server behaviour as the main outcome, reported as a behaviour score. It is difficult, however, to translate the practical implications of such a measure to injury risk and/or alcohol consumption. A previously published systematic review of primary prevention interventions for alcohol misuse in young people, by Foxcroft 2002, described the difficulty in judging relative effectiveness of different interventions, when the evaluations report different outcomes and the public health relevance of these different outcomes is unknown. Foxcroft 2002 highlighted the need for a systematic review of the evidence for subsequent alcoholrelated problems provided by such indicators, which should lead to greater clarity over the type of measures to be used in future evaluations.

The low rating of methodological quality of the included studies is undoubtedly a reflection of the numerous challenges posed by conducting research in this area; is it expected that many public health studies will never meet all of the criteria for quality (Jackson 2004). The nature of the interventions, participants and outcomes under investigation can prohibit elements of study design, such as blinding and randomisation, which are important elements for study validity. Thus our overall 'weak' rating may be unsurprising. However, it is important that researchers attempt to maximise their studies' validity, when it is feasible. For example, of the six randomised trials included in this review, none reported using adequate allocation concealment; yet allocation concealment is always possible, irrespective of topic (Schulz 1994).

\section{Findings in relation to previous systematic reviews}

A previous systematic review by Shults 2001 examined the effectiveness of server training in reducing drink driving. Five con- 
trolled studies were included (Gliksman 1993; Holder 1994; Lang 1998; Russ 1987; Saltz 1987), three of which were non-randomised designs with patron alcohol consumption as an outcome. The review concluded that 'there is sufficient evidence that faceto-face server training, when accompanied by strong and active management support, is effective in reducing the level of intoxication in patrons' and is 'likely to have a desirable effect on alcohol impaired driving if the affected patrons cease drinking or continue drinking in relatively safe environments after leaving the drinking establishment'. In addition to the five articles previously identified by Shults 2001, this present systematic review includes a further nine studies of server training, two of which were randomised trials measuring patron alcohol consumption as an outcome. The additional studies provide no good evidence that the intervention is effective in preventing injury or reducing patron alcohol consumption. Therefore the existence of 'sufficient evidence' for the effectiveness of server training in reducing alcohol intoxication might now be considered tentative.

Shults' review focused on trials of server training in reducing drink driving, no other systematic reviews of server setting interventions have been located to enable comparison.

\section{Policy implications}

Interventions such as server training, which effectively place responsibility of sensible alcohol consumption on the server, may be limited as an effective strategy due to the nature of the alcoho industry and server work. There are potential difficulties associated with interventions for which implementation is controlled by the alcohol industry; if interventions compromise profit margins, it is reasonable to suggest that the alcohol industry will resist their implementation, without the presence of incentives and/or legislation. Additionally, it should be considered that bar work is generally low paid, and is a profession with a high turnover of staff. Such a highly mobile workforce makes the process of training difficult, unless training was mandated and completion of training was a prerequisite for employment. Effective implementation amongst servers may also be resisted without financial reward for the additional responsibility placed upon them, in an already low paid and often stressful environment.

The relatively poor compliance with the interventions, particularly the server training interventions, may suggest a feeling of ambivalence or lack of belief in the benefits of intervention. Future studies should consider ways to improve uptake and intervention compliance, such as by involvement of relevant parties in the study design. Compliance with the assigned intervention is important. Non-compliance reduces the statistical power of a trial to detect any true effect of the study intervention. In such cases it is not certain that an observed non-significant effect is due to an ineffective intervention or to its incomplete implementation. This information also indicates the feasibility of delivering the intervention in the real life setting; if integrity of implementation in a study situation is low it is likely to be poor in practice (Jack- son 2005a). This apparent compliance problem may have implications for the effectiveness of policies outlined in the UK Government's 'Alcohol Harm Reduction Strategy for England' (Strategy Unit 2004), in which there is a focus on voluntary agreements with the alcohol industry in preference to a mandated approach. The findings of this systematic review suggests that it is likely that the UK Government will be required to take a firmer stance with the alcohol industry in the adoption of harm prevention policy, if any discernible effect is to be seen. However, the challenge is that usually an intervention is only likely to be made mandatory once evidence for effectiveness has been established. The Government's preference for a voluntary approach with the alcohol industry has lead to concern in regard to the lobbying influence of the industry on public policy (MacQueen 2004), which worryingly might be likened to that exhibited by the tobacco industry on anti-smoking policy.

It is not the aim of this systematic review to make policy recommendations; policy making is a complex process in which examination of the evidence base, whilst crucial, is just one component. This review has been prepared recognising that different people interpret evidence differently; therefore the included studies have been reviewed and presented in a systematic and explicit way, so that readers are able to examine the evidence and reach their own conclusions, applicable to their own setting. A lack of evidence for effect of an approach should not necessarily prohibit its adoption; interventions in the server setting should be considered in relation to the effectiveness and cost-effectiveness of alternative alcohol harm prevention interventions, in the context of the particular setting of interest.

\section{A U THORS' CONCLUSIONS}

\section{Implications for practice}

There is no reliable evidence that interventions in the alcohol server setting are effective in reducing injury. Lack of compliance with interventions seems to be a particular problem; hence mandated interventions or those with associated incentives for compliance, may be more likely to show an effect.

The apparent compliance problem is likely to have implications for the success of proposed strategies outlined in the Alcohol Harm Strategy for England, in which there is a preference for voluntary agreements with the alcohol industry in regard to intervention implementation. It is probable that such voluntary interventions will suffer limited uptake and thus have limited effect.

\section{Implications for research}

The methodology of future evaluations needs to be improved. Randomised controlled trials, with adequate allocation concealment and blinding, are needed to improve the evidence base. Fur- 
ther well conducted non-randomised trials are also needed, when random allocation is not feasible.

The focus of research should be broadened to investigate the effectiveness of interventions other than server training, where previous research dominates.

When the collection of injury outcome data is not feasible, research is needed to identify the most useful proxy indicators.

Finally, future studies should be designed with the aim of contributing to the evidence base, not simply as stand alone evaluations.

\section{POTENTIAL CONFLICTOF I N T E R E S T}

None known.

\section{ACKNOWLEDGEMENTS}

Thanks to Ian Roberts, Tim Collier and Julie Mytton for method- ological support, Karen Blackhall for advice on database searching, and Rebecca Ivers for managing the editorial processes for the review.

Thanks also to the authors of the included studies for providing additional information on request, and to the peer referees for their helpful comments.

The development of this review was supported by funding from the Alcohol Education Research Council, UK.

\section{SOURCESOFSUPPORT}

\section{External sources of support}

- Cochrane Health Promotion \& Public Health field AUSTRALIA

- Alcohol Education Research Council UK

Internal sources of support

- No sources of support supplied

\section{R E F E R E N C E S}

\section{References to studies included in this review}

Boots 1995 \{published data only\}

Boots K, Midford R. Promoting Safe Parties: Evaluation of the 1993 Geraldton Partysafe Campaign. National Centre for Research into the Prevention of Drug Abuse, Curtin University of Technology 1995.

Buka 1999 \{published data only\}

Buka SL, Birdthistle IJ. Long-term effects of a community-wide alcohol server training intervention. Journal of Studies on Alcohol 1999; 60:27-36.

Casteel 2004 \{published data only\}

Casteel C, Peek-Asa C, Howard J, Kraus JF. Effectiveness of crime prevention through environmental design in reducing criminal activity in liquor stores: a pilot study. Journal of Occupational and Environmental Medicine 2004;46:450-8.

Felson 1997 \{published data only\}

Felson M, Berends R, Richardson B, Veno A. Reducing pub hopping and related crime. Criminal Justice Press 1997.

Gliksman 1993 \{published data only\}

Gilksman L, McKenzie D, Single E, Douglas R, Brunet S, Moffatt $\mathrm{K}$. The role of alcohol providers in prevention: an evaluation of a server intervention programme. Addiction 1993;88:1195-203.

Graham 2004 \{published data only\}

Graham K, Osgood DW, Zibrowski E, Purcell J, Gliksman L, Leonard K, et al.The effect of the Safer Bars programme on physical aggression in bars: results of a randomized controlled trial. Drug and Alcohol Review 2004;23:23-41.
Holder 1994 \{published data only\} Holder HD, Wagenaar AC. Mandated server training and reduced alcohol-involved traffic crashes: a time series analysis of the Oregon experience. Accident Analysis and Prevention 1994;26(1):89-97.

Howard-Pitney 1991 \{published data only\}

Howard-Pitney B, Johnson MD, Altman DG, Hopkins, Hammond N. Responsible alcohol service: a study of server, manager and environmental impact. American Journal of Public Health 1991;81(2): 197-9.

Johnsson 2003 \{published data only\} Johnsson KO, Berglund M. Education of key personnel in student pubs leads to a decrease in alcohol consumption among the patrons: a randomized controlled trial. Addiction 2003;98:627-33.

Krass 1994 \{published data only\}

Krass I, Flaherty B. The impact of a responsible service training on patron and server behaviour: a trial in Waverley (Sydney). Health Promotion Journal of Australia 1994;4(2):51-8.

Lacey 2000 \{published data only\} Lacey JH, Jones RK, Anderson EW. Evaluation of a Full-Time Ride Service Program. Aspen, Colorado's Tipsy Taxi Service. National Highway Traffic Safety Administration 2000; Vol. DOT HS 809155.

Lang 1998 \{published data only\}

*Lang E, Stockwell T, Rydon P, Beel A. Can training bar staff in responsible serving practices reduce alcohol-related harm?. Drugs and Alcohol Review 1998;17:39-50.

Stockwell T, Rydon P, Lang E, Beel A. An evaluation of the 'Freo Respects You' responsible alcohol service project. National Centre 
for Research into the Prevention of Drug Abuse, Curtin University, Perth, Western Australia November 1993.

McKnight 1991 \{published data only\}

McKnight AJ. Factors influencing the effectiveness of server-intervention education. Journal of Studies in Alcohol 1991;52(5):389-97.

McLean 1994 \{published data only\}

McLean S, Wood L, Montgomery I, Davidson J, Jones M. Promotion of responsible drinking in hotels. Drug and Alcohol Review 1994;13: $247-55$.

Russ 1987 \{published data only\}

Russ NW, Geller ES. Training bar personnel to prevent drunken driving: a field evaluation. American Journal of Public Health 1987; 77(8):952-4.

Saltz 1987 \{published data only\}

Saltz RF. The roles of bars and restaurants in preventing alcoholimpaired driving. An evaluation of server intervention. Evaluation \& Health Professions 1987;10(1):5-27.

Saltz 1997 \{published data only\}

Grube JW. Preventing sales of alcohol to minors: results from a community trial. Addiction 1997;92(Suppl. 2):S251-60.

Holder HD, Gruenewald PJ, Ponicki WR, Treno AJ, Grube JW, Saltz RF, et al.Effect of community-based interventions on high-risk drinking and alcohol-related injuries. JAMA 2000;284(18):2341-7.

Holder HD, Saltz RF, Grube JW, Treno AJ, Reynolds RI, Voas RB, et al.Summing up: lessons from a comprehensive community prevention trial. Addiction 1997;92(Suppl. 2):S293-301.

Holder HD, Saltz RF, Grube JW, Voas RB, Gruenewald PJ, Treno AJ. A community prevention trial to reduce alcohol-involved injury and death: overview. Addiction 1997;95(Suppl. 2):S155-71.

* Saltz RF, Stanghetta P. A community-wide Responsible Beverage Service program in three communities: early findings. Addiction 1997;92(Suppl. 2):S237-49.

Voas RB, Holder HD, Gruenewald PJ. The effect of drinking and driving interventions on alcohol-involved traffic crashes within a comprehensive community trial. Addiction 1997;92(Suppl. 2):S22136.

Toomey 2001 \{published data only\}

Toomey TL, Waganeer AC, Gehan JP, Kilian G, Murray DM, Perry CL. Project ARM: Alcohol risk management to prevent sales to underage and intoxicated patrons. Health Education \& Behaviour 2001; 28(2):186-99.

Wallin 2002 \{published data only\}

*Wallin E, Gripenberg, Andreasson S. Too drunk for a beer? A study of overserving in Stockholm. Addiction 2002;97:901-7.

Wallin E, Norstrom T, Andreasson S. Alcohol prevention targeting licensed premised: a study of effects on violence. Journal of Studies on Alcohol 2003;64:270-7.

Warburton 2000 \{published data only\}

Warburton AL, Shepherd JP. Effectiveness of toughened glassware in terms of reducing injury in bars: a randomised controlled trial. Injury Prevention 2000;6:36-40.

\section{References to studies excluded from this review}

Boots 1994

Boots K. The designated driver program: an outcome evaluation. Health Promotion Journal of Australia 1994;4:1036-73.

\section{Boots 1999}

Boots K, Midford R. 'Pick-a-Skipper': an evaluation of a designated driver program to prevent alcohol-related injury in a regional Australian city. Health Promotion International 1999;14(4):337-45.

\section{Brigham 1995}

Brigham TA, Meier SM, Goodner V. Increasing designated driving with a program of prompts and incentives. Journal of Applied Behaviour Analysis 1995;28:83-4.

\section{Chikritzhs 2002}

Chikritzhs T, Stockwell T. The impact of later trading hours for Australian public houses (hotels) on levels of violence. Journal of Studies on Alcohol 2002;63:591-9.

\section{Hingson 1996}

Hingson R, McGovern T, Howland J, Heeren T, Winter M, Zakocs R. Reducing alcohol-impaired driving in Massachusetts: the Saving Lives Program. American Journal of Public Health 1996;86(6):791-7.

\section{Hocking 1983}

Hocking B. A controlled trial of supervisor training for an industrial alcohol program. Australian Alcohol/Drug Review 1983;2(2):100-6.

\section{Homel 2004}

Homel R, Carvolth R, Hauritz M, Mcllwain G, Teague R. Making licensed venues safer for patrons: what environmental factors should be the focus of interventions?. Drug and Alcohol Review 2004;23: $19-29$

Licata 2002

Licata M, Gillham K, Campbell E. Health promotion practices of restaurant and cafés in Australia: changes from 1997 to 2000 using an annual telemarketing intervention. Health Promotion International 2002;17(3):255-62.

\section{Maguire 2003}

Maguire M, Nettleton $\mathrm{H}$. Reducing alcohol-related violence and disorder: an evaluation of the 'TASC' project. Home Office Research Study 2652003.

\section{McKnight 1994}

McKnight AJ, Streff FM. The effect of enforcement upon server of alcohol to intoxicated patrons of bars and restaurants. Accident Analysis \& Prevention 1994;26(1):79-88.

\section{Norström 2003}

Norström T, Skog O. Saturday opening of alcohol retail shops in Sweden: an impact analysis. Journal of Studies on Alcohol 2003;64 (393-401)

\section{Reilly 1998}

Reilly D, Van Beurden E, Mitchell E, Dight R, Scott C, Beard J. Alcohol education in licensed premises using brief intervention strategies. Addiction 1998;93(3):385-98.

\section{Simons-Morton 1997}

Simons-Morton BG, Snider Cummings S. Evaluation of a local designated driver and responsible server program to prevent drinking and driving. Journal of Drug Education 1997;27(4):321-33. 


\section{Wagenaar 1991}

Wagenaar AC, Holder HD. Effects of alcoholic beverage server liability on traffic crash injuries. Alcoholism: Clinical and Experimental Research 1991;15(6):942-7.

\section{Wagenaar 2000}

Wagenaar AC, Murray DM, Toomey TL. Communities Mobilizing for Change on Alcohol (CMCA): effects of a randomized trial on arrests and traffic crashes. Addiction 2000;95(2):209-17.

\section{Wundersitz 2002}

Wundersitz LN. An evaluation of coin-operated breath testing machines in South Australian licensed premises. Proceedings of the 16th International Conference on Alcohol, Drugs and Traffic Safety T2002, Montréal, Québec, Canada. 2002:817-23.

\section{References to studies awaiting assessment}

\section{Haworth 1997}

Haworth N, Bowland L, Vulcan P, Finch C. Pilot study of promotion of public breath testing. Monash University Accident Research Centre 1997; Vol. Report No. 117

\section{Molof 1995}

Molof MJ, Dresser J, Ungerleider S, Kimball C, Schaefer J. Assessment of year-round and holiday ride service programs. National Highway Traffic Safety Administration, Washington, DC 1995; Vol. DOT HS 808203.

\section{South 1991}

South D, Delaporte H, Nolan C. The development and evaluation of training programs in the responsible service of alcohol in Victoria. Melbourne: VicRoads 1991.

\section{Additional references}

\section{Alderson 2002}

Alderson P, Green S. Open learning material for reviewers. Cochrane Collaboration 2002

Babor 2003

Babor T, Caetano R, Casswell S, Edwards G, Giesbrecht N, Graham $\mathrm{K}$, et al.Alcohol: no ordinary commodity. Oxford: Oxford University Press, 2003.

Berlin 1997

Berlin JA. Does blinding of readers affect the results of meta-analyses? Lancet 1997;350:185-6.

Britton 2001

Britton A, McPherson K. Mortality in England and Wales attributable to current alcohol consumption. Journal of Epidemiology and Community Health 2001;55:383-8.

Deeks 2003

Deeks JJ, Dinnes JJ, D’Amico R, Sowden AJ, Sakarovitch C, Song F, et al.Evaluating non-randomised intervention studies. Health Technology Assessment 2003; Vol. 7, issue 27.

Egger 2001

Egger M, Davey Smith G, O’ Rouke K. Rationale, potential, and promise of systematic reviews. In: EggerM, Davey SmithG, AltmanDG editor(s). Systematic reviews in health care: meta-analysis in context. Cornwall: BMJ Publishing Group, 2001.

English 1996

English DR, Holman CDJ, Milne E, Winter MG, Hulse GK, Codde JP, et al.The quantification of drug caused morbidity and mortality in Australia, 1995 edition. Reported in: International guide for monitoring alcohol consumption and related harm. WHO 2000.

\section{Foxcroft 2002}

Foxcroft DR, Ireland D, Lowe G, Breen R. Primary prevention for alcohol misuse in young people. The Cochrane Database of Systematic Reviews 2002, Issue 3.Art. No.: CD003024.. DOI: 10.1002/14651858.CD003024..

\section{Graham 1997}

Graham K, Homel R. Creating safer bars. In: PlantM, SingleE, StockwellT editor(s). Alcohol: Minimising the harm. New York: Free Association Books, 1997.

\section{Graham 2000}

Graham K. Preventive interventions for on-premise drinking: a promising but underresearched area for prevention. Contemporary Drug Problems 2000;27:593-667.

Higgins 2005

Higgins JPT, Green S, editors. Assessment of study quality. Cochrane Handbook for Systematic Reviews of Interventions 4.2.5 [updated May 2005]. The Cochrane Library. Chichester, UK: John Wiley \& Sons, Ltd, Issue 3, 2005.

\section{Homel 1992}

Homel R, Tomsen S. Hot spots for violence: the environment of pubs and clubs. Homicide: patterns, prevention and control: proceeding of a conference held 12-14 May 1992, Canberra. 1992

Homel 2001

Homel R, Mcllwain G, Carvolth R. Creating safer drinking environments. In: HeatherN, PetersT, StockwellT editor(s). International Handbook of Alcohol Dependence and Problems. Chichester: John Wiley \& Sons Ltd, 2001.

\section{Hope 2004}

Hope A. Alcohol policy and young people. The Globe 2004; Vol. http://www.ias.org.uk/publications/theglobe/04issue1, 2/globe0412_p15.html.

\section{Jackson 2004}

Jackson N, Waters E, and the Guidelines for Systematic Reviews of Health Promotion and Public Health Intervention Taskforce. The challenges of systematically reviewing public health interventions. Journal of Public Health 2004;26(3):303-7.

\section{Jackson 2005a}

Jackson N, Waters E for the Guidelines for Systematic Reviews of Health Promotion and Public Health Interventions Taskforce. Guidelines for Systematic reviews of health promotion and public health interventions. Deakin University, Australia April 2005; Vol. Version 1.2 .

\section{Jackson 2005b}

Jackson N, Waters E, for the Guidelines for Systematic Reviews in Health Promotion and Public Health Taskforce. Criteria for the systematic review of health promotion and public health intervention. Health Promotion International 2005;20(4):367-74.

\section{Jernigan 2000}

Jernigan DH, Monteiro M, Room R, Saxena S. Towards a global alcohol policy: alcohol, public health and the role of WHO. Bulletin of the World Health Organisation 2000;78(4):491-9. 


\section{MacQueen 2004}

MacQueen R. Alcohol evidence and policy: Harm reduction strategy

is triumph of spin over substance. BMJ 2004;328:1202.

\section{Murray 1997a}

Murray CJL, Lopez AD. Alternative projections of mortality and disability by cause 1990-2020: Global Burden of Disease Study. The Lancet 1997;349:1498-504.

\section{Murray 1997b}

Murray CJL, Lopez AD. Global mortality, disability, and the contribution of risk factors: Global Burden of Disease Study. The Lancet 1997;349:1436-42.

\section{O'Donnell 1985}

O'Donnell M. Research on drinking locations of alcohol-impaired drivers: implications for prevention policies. Journal of Public Health Policy 1985;6:510-25.

\section{Peden 2002a}

Peden M, McGee K, Sharma G. The injury chart book: a graphical overview of the global burden of injuries. World Health Organization 2002.

\section{Peden 2002b}

Peden M, McGee K, Krug E (Eds). Injury: A leading cause of the global burden of disease, 2000. World Health Organization 2002

\section{Poznyak 2001}

Poznyak V, Peden M. WHO Collaborative Study on Alcohol and Injuries; Protocol. WHO 2001.

Rehm 2003

Rehm J, Room R, Monteiro M, Gmel G, Graham K, Rehn N, et al.Alcohol as a risk factor for global burden of disease. European Addiction Research 2003;9:157-64

\section{Schulz 1994}

Schulz KF, Chalmers I, Grimes DA, Altman DG. Assessing the Quality of Randomization From Reports of Controlled Trials Published in Obstetrics and Gynecology Journals. JAMA 1994;272:125-8.

\section{Schulz 1995}

Schulz KF, Chalmers I, Hayes RJ, Altman DG. Empirical evidence of bias. Dimensions of methodological quality associated with estimates of treatment effects in controlled trials. JAMA 1995;273(5):408-12.

\section{Shults 200}

Schults R, Elder RW, Sleet DA, Nichols JL, Alao MO, Carande-Kulis VG, et al.Reviews of Evidence Regarding Interventions to Reduce Alcohol-Impaired Driving. American Journal of Preventive Medicine 2001;21:4S

\section{Soares 2004}

Soares HP, Daniels S, Kumar A, Clarke M, Scott C, Swann S, et al.Bad reporting does not mean bad methods for randomised controlled trials preformed by the Radiation Therapy Oncology Group. BMJ 2004:328:22-4.

\section{Stockwell 2001}

Stockwell T. Responsible alcohol service: lessons from evaluations of server training and policing initiatives. Drug and Alcohol Review 2001;20:257-65.

\section{Strategy Unit 2004}

Strategy Unit. Alcohol harm reduction strategy for England. Prime Minister's Strategy Unit. Cabinet Office 2004.

\section{Thomas 2003}

Thomas H. Quality assessment tool for quantitave studies. Effective Public Health Practice Project 2003.

\section{Wears 2002}

Wears RL. Statistical methods for analyzing cluster and cluster-randomized data. Academic Emergency Medicine 2002;9(4):330-41.

\section{WHO 1999}

WHO. Global Status Report on Alcohol: Global Overview. World Health Organisation 1999

\section{WHO 2002}

WHO. Reducing risks to health and promoting healthy life. World Health Report 2002.

*Indicates the major publication for the study

T A B L E S

\section{Characteristics of included studies}

\begin{tabular}{ll}
\hline Study & Boots $\mathbf{1 9 9 5}$ \\
\hline Methods & Non-randomised study, unit of allocation = town. \\
\hline Participants & $\begin{array}{l}\text { Western Australia. } \\
\text { Experimental = one town, Geraldton. } \\
\text { Control = one town, Bunbury. }\end{array}$ \\
\hline Interventions & $\begin{array}{l}\text { Health promotion intervention } \\
\text { The 'Partysafe' campaign conducted in December 1993, for 23 days until New Year's day. Aim to encourage } \\
\text { the responsible serving of alcohol at parties by providing 'Partysafe' Christmas cards with every purchase } \\
\text { of takeaway liquor. The cards listed four tips for having a safe party; 1) Provide food 2) Ensure that non- }\end{array}$ \\
& $\mathbf{1 7}$ \\
\hline $\begin{array}{l}\text { Interventions in the alcohol server setting for preventing injuries (Review) } \\
\text { Copyright } \odot \mathbf{2 0 0 8} \text { The Cochrane Collaboration. Published by John Wiley \& Sons, Ltd }\end{array}$
\end{tabular}




\section{Characteristics of included studies (Continued)}

alcoholic and low alcoholic drinks are available 3) Serve alcohol responsibly 4) Consider guests' transport needs.

The tips were also featured in local media.

Ten licensed liquor takeaway premises in Geraldton participated in the 'Partysafe campaign'.

Bunbury received no intervention.

\begin{tabular}{ll}
\hline Outcomes & Drinkers' self-reported knowledge and behaviour, collected by random telephone interviews of town residents. \\
\hline Notes & \\
\hline Allocation concealment & D - Not used \\
\hline
\end{tabular}

\begin{tabular}{ll} 
Study & Buka 1999 \\
\hline Methods & Non-randomised study, unit of allocation = community. \\
\hline Participants & Rhode Island; USA. \\
& Three communities; one experimental and two control sites. \\
& Experimental = containing 51 bars \\
& Control site A = containing 26 bars \\
& Control site B = containing 26 bars \\
\hline Interventions & Server training \\
& CAAIPP alcohol server training. Twenty-four training courses were held, each lasting five hours, with 5-15 \\
& servers attending each course. The training curriculum was developed from the National Highway Traffic \\
& Safety Administration. The training emphasised training by peer servers; each session was co-facilitated by a \\
& server and an alcohol treatment/prevention professional from the community. The purpose of the training \\
& was to provide servers with the knowledge and skills required to prevent patrons from becoming intoxicated, \\
prevent service of alcohol to minors, identify and stop service to intoxicated patrons and help prevent injuries \\
to those individuals as well as informing servers of their legal liability if they fail to obey dram shop laws. \\
Control communities were not exposed to CAAIPP training. \\
\hline Self reported server behaviour, measured by a Desired Server Behaviour Index. \\
\hline Outcomes
\end{tabular}

Study Casteel 2004

\begin{tabular}{ll}
\hline Methods & Controlled before-and-after study, unit of allocation = liquor stores \\
\hline Participants & Santa Monica, CA; USA \\
& Experimental = 9 liquor stores. \\
& Control = 13 liquor stores. \\
\hline
\end{tabular}

Interventions Environmental intervention

Based on Crime Prevention Through Environmental Design concepts (that criminal activity can be reduced by modifying the business environment). Basic elements included keeping a minimal amount of cash in the till, ensuring good visibility into and out of premises, bright interior and exterior lighting, escape routes and training of employees in how to respond to robbery and shoplifting events. From a baseline assessment, an individualised safety plan was designed. Stores also received manuals, copy of the plan and other educational materials. The Californian Occupational Safety \& Health Administration implemented the intervention.

Control premises received no intervention.

\begin{tabular}{ll}
\hline Outcomes & Injury (criminal activity) obtained from police records. \\
\hline Notes & \\
\hline Allocation concealment & D - Not used \\
\hline Interventions in the alcohol server setting for preventing injuries (Review) \\
Copyright $\odot 2008$ The Cochrane Collaboration. Published by John Wiley \& Sons, Ltd
\end{tabular}




\section{Characteristics of included studies (Continued)}

\begin{tabular}{|c|c|}
\hline Study & Felson 1997 \\
\hline Methods & Controlled before-and-after study, unit of allocation = area. \\
\hline Participants & $\begin{array}{l}\text { Victoria, Australia. } \\
\text { Experimental=City of Geelong. } \\
\text { Control=Greater Geelong and the metropolitan area of six other Victorian cities (Warrnambool, Mildura, } \\
\text { Ballarat, Bendigo, Wangaratta, Morwell). }\end{array}$ \\
\hline Interventions & $\begin{array}{l}\text { Policy intervention } \\
\text { Twelve-point policy for preventing bar-hopping and reducing violence and other crime in and around licensed } \\
\text { premises. Development of a policy (the Accord) for premises. The focus of the policy was to reduce the } \\
\text { movement of patrons among bars and attempt to reduce overall alcohol consumption of patrons, and contain } \\
\text { that consumption within safer settings. Policy provisions; } \\
\text { 1) cover charges to entry after } 11.00 \text { pm } \\
\text { 2) denial of free re-entry to those who had exited } \\
\text { 3) no free drinks } \\
\text { 4) limitations on promotions } \\
\text { 5) no extended happy-hours } \\
\text { 6) uniform minimum price per drink } \\
\text { 7) enforcing of bylaws against drinking or possession of open liquor containers on the streets 8) seizing faked, } \\
\text { altered or borrowed ID cards misused by young people } \\
\text { 9) issuing summons for use of illegal ID cards } \\
\text { 10) alcohol-free entertainment provided for underage youths on selected premises } \\
\text { 11) calling taxis or friends for rides homes } \\
\text { 12) uniform adherence to liquor laws by service personnel. } \\
\text { Implementation of policy was led by the police }\end{array}$ \\
\hline Outcomes & Injury (serious assault rate) obtained from police records. \\
\hline \multicolumn{2}{|l|}{ Notes } \\
\hline Allocation co & D - Not used \\
\hline
\end{tabular}

\begin{tabular}{ll} 
Study & Gliksman $\mathbf{1 9 9 3}$ \\
\hline Methods & Randomised trial, unit of allocation = bar. \\
\hline Participants & $\begin{array}{l}\text { Thunder Bay, Ontario; Canada. } \\
\text { Experimental = 4 bars } \\
\text { Control = 4 bars }\end{array}$ \\
\hline Interventions & $\begin{array}{l}\text { Server training } \\
\text { Server intervention training developed by the Addiction Research Foundation of Ontario. Managers were } \\
\text { informed of their legal obligations and encouraged to establish policies for the sale of alcohol in their } \\
\text { establishments. The servers were then familiarised with the new policy and instructed in responsible serving } \\
\text { practices. The emphasis of the programme was on preventing intoxication rather than intervening once a } \\
\text { patron has reached intoxication. } \\
\text { Control bars received no intervention. }\end{array}$ \\
\hline Outcomes & $\begin{array}{l}\text { Knowledge (measured in trained only) using questionnaires. } \\
\text { Observed server behaviour (using pseudo-drunks). }\end{array}$ \\
\hline Notes & \\
\hline Allocation concealment & D - Not used \\
\hline
\end{tabular}

Study

Graham 2004

Methods

Randomised trial, unit of allocation $=$ bar

Participants Toronto, Canada

Interventions in the alcohol server setting for preventing injuries (Review)

Copyright ( 2008 The Cochrane Collaboration. Published by John Wiley \& Sons, Ltd 


\section{Characteristics of included studies (Continued)}

\begin{tabular}{ll} 
& Experimental = 26 bars \\
& Control = 12 bars \\
\hline Interventions & Server training The 'Safer Bars' intervention, aim to reduce aggression in bars. Two main components; \\
1) risk assessment workbook (alerting environmental factors); this was drawn directly from published research \\
on alcohol-related aggression; alerted the bar owner to environmental factors e.g. potential problems relating \\
to the floor plan of the bar and the role of environmental expectations. \\
2) three hour training programme also drawn from bar-room research, to identify common types of incidents \\
of aggression and staff behaviours contributing to aggression as well as staff behaviours that are effective \\
in avoiding and defusing aggression. The training covered; i) recognising the early signs of aggression and \\
intervening early ii) assessing the situation and planning a response iii) techniques for preventing loss of \\
control due to anger iv) body language and non-verbal techniques v) responding to problem situations vi) \\
legal issues relating to managing aggression and problem behaviour Staff were paid for participation in the \\
study. \\
Observed aggression exhibited by patrons and staff. \\
\hline Outcomes & Analyses were adjusted for clustering using Hierarchical Linear Modelling (HLM). \\
\hline Notes & D - Not used
\end{tabular}

Study

Holder 1994

Methods

Controlled before-and-after, unit of allocation = US State

Participants

USA

Experimental $=$ Oregon state

Control $=47$ remaining US states

Interventions

Server training

Mandated server training policy versus no mandated server training policy. The one day training course covered seven areas;

1) effect of alcohol on the body

2) interaction effects of alcohol with other drugs (prescription and illicit)

3) problem drinking and alcoholism

4) state of Oregon's service laws

5) drinking and driving laws in Oregon and legal liability issues

6) effective server intervention techniques

7) alcohol marketing practices for responsible alcohol service

A standardised written test must be passed by all participants to obtain a permit to serve alcohol.

\begin{tabular}{ll}
\hline Outcomes & Injury (single vehicle night-time crashes) obtained from official records. \\
\hline Notes & \\
\hline Allocation concealment & D - Not used \\
\hline
\end{tabular}

\section{Study}

Howard-Pitney 1991

Methods

Non-randomised study, unit of allocation = bar

Participants

Utah, USA.

Experimental $=26$ premises

Control $=14$ premises

Interventions

Server training One-day training session. Servers and managers attended separate programmes that taught the physical and behavioural effects of alcohol and strategies for providing a more responsible alcohol service; taught the physical and behavioural effects of alcohol, and strategies for providing more responsible alcohol service. Managers received instruction on developing company policies to change the drinking environment.

\begin{tabular}{ll}
\hline Outcomes & Observed server behaviour. \\
& Knowledge (in trained group only) measured using questionnaires.
\end{tabular}




\section{Characteristics of included studies (Continued)}

Notes

Allocation concealment $\mathrm{D}$ - Not used

\begin{tabular}{ll} 
Study & Johnsson $\mathbf{2 0 0 3}$ \\
\hline Methods & Randomised trial, unit of allocation = bar. \\
\hline Participants & Lund University, Sweden \\
& Experimental = six student bars \\
& Control = six student bars \\
\hline Interventions & Server training \\
& Training programme based on the Alcohol Skills Training Program (ASTP) and the Swedish version of the \\
& Responsible Beverage Service. Bartenders in 'key positions' attended educational programme (n=40), these \\
& participants were responsible for the total amount of alcohol served in the bar during an evening, responsible \\
& for spreading the educational programme to their colleagues, responsible for creating guidelines for serving \\
& beverages responsibly. The focus of the programme was on the servers' own reation to alcohol. \\
& Control received no server training. \\
\hline Outcomes & Patron behaviour (alcohol consumption, determined by breath tests). \\
\hline Notes & Not professional servers (did not receive monetary payment for service). \\
\hline Allocation concealment & D - Not used \\
\hline
\end{tabular}

\begin{tabular}{|c|c|}
\hline Study & Krass 1994 \\
\hline Methods & Randomised trial, unit of allocation = bar. \\
\hline Participants & $\begin{array}{l}\text { Waverley, Australia. } \\
\text { Experimental = } 4 \text { bars } \\
\text { Control = } 4 \text { bars }\end{array}$ \\
\hline Interventions & $\begin{array}{l}\text { Server training } \\
\text { Four hour training package for all staff of licensed alcohol serving establishments. The aim of which was to } \\
\text { equip participants with the knowledge and skills necessary to comply with the Liquor Act and to develop } \\
\text { responsible service practices within licensed premises. } \\
\text { Topics included in the package; } \\
\text { 1) The New South Wales Liquor Act } \\
\text { 2) Definition of Responsible Hospitality Practices } \\
\text { 3) Identification of Responsible Hospitality Practices } \\
\text { 4) Facts about alcohol } \\
\text { 5) Responsible promotions } \\
\text { 6) Preventing under-age drinking } \\
\text { 7) Recognising intoxication } \\
\text { 8) Preventing harmful consequences of intoxication } \\
\text { 9) Skills for the refusal or modification of requested service. } \\
\text { Control group received no server training. }\end{array}$ \\
\hline Outcomes & $\begin{array}{l}\text { Behaviour of patrons (alcohol consumption, measured by breath test and interview). } \\
\text { Knowledge (in trained group only) measured using questionnaires. }\end{array}$ \\
\hline \multicolumn{2}{|l|}{ Notes } \\
\hline Allocation concealment & D - Not used \\
\hline
\end{tabular}

Study

Lacey 2000

Methods Controlled before-and-after, unit of allocation = area.

Participants

Interventions in the alcohol server setting for preventing injuries (Review)

Copyright $\odot 2008$ The Cochrane Collaboration. Published by John Wiley \& Sons, Ltd 


\begin{tabular}{|c|c|}
\hline \multicolumn{2}{|c|}{ Characteristics of included studies (Continued) } \\
\hline & Experimental $=$ Pitney County, Colorado \\
\hline & Control $=$ two nearby jurisdictions \\
\hline \multirow[t]{3}{*}{ Interventions } & Drink driving service \\
\hline & 'Tipsy Taxi' service (operated 24 hours a day, 365 days a year) providing a free ride home for persons too \\
\hline & Control areas had no such service. \\
\hline Outcomes & Injury (crashes), source of data not reported. \\
\hline \multicolumn{2}{|l|}{ Notes } \\
\hline Allocation concealment & D - Not used \\
\hline Study & Lang 1998 \\
\hline Methods & Non-randomised study, unit of allocation = bar. \\
\hline \multirow[t]{3}{*}{ Participants } & Australia \\
\hline & Experimental $=7$ premises. \\
\hline & Control $=7$ premises. \\
\hline \multirow[t]{9}{*}{ Interventions } & Server training \\
\hline & Responsible service training programme, approximately $1-2$ hours long. Participants were paid their regular \\
\hline & Core components; \\
\hline & 1) laws regarding the serving of juveniles and drunken people \\
\hline & 2) recognising the signs of intoxication \\
\hline & 3) strategies for dealing with drunken customers* \\
\hline & 4) alcohol and its effect \\
\hline & 5) developing responsible house policies* \\
\hline & (*elements were not fully covered in all training workshops and in some cases omitted) \\
\hline \multirow[t]{5}{*}{$\overline{\text { Outcomes }}$} & Drink driving offences (obtained from police reports). \\
\hline & Behaviour of patrons (alcohol consumption, measured by breath test). \\
\hline & Self-reported server behaviour (measured by questionnaires). \\
\hline & Observed server behaviour (using pseudo-drunks). \\
\hline & Knowledge (in trained servers only) measured by questionaires. \\
\hline Notes & Inconsistencies in the standard of training and coverage of topics reported. \\
\hline Allocation concealment & $\mathrm{D}-$ Not used \\
\hline
\end{tabular}

\begin{tabular}{ll} 
Study & McKnight 1991 \\
\hline Methods & Non-randomised study, unit of allocation = bar. \\
\hline Participants & USA \\
& Experimental = 100 premises in eight sites across the USA (Lafayette, Louisiana; Washtenaw County, Michi- \\
& gan; York, Pennsylvania; Houston, Texas; Springfield, Massachusetts; Newark/Newcastle, Delaware; Clin- \\
& ton/Muscatine/Bettendorf, Iowa; Everett/Lynwood/Marysville, Washington). \\
& Control = 138 premises. \\
\hline Interventions & $\begin{array}{l}\text { Server training } \\
\text { 'Program of Responsible Alcohol Service' developed by the National Public Service Research Institute. Six }\end{array}$ \\
& hours in length; first three hours were intended for both servers and managers and dealt with the need for \\
& responsible alcohol service, ways of preventing customers from becoming intoxicated and methods on inter- \\
& vening with patrons who have already become intoxicated. The final three hours were intended for managers \\
& only and included role plays of intervention with intoxicated patrons, the formulation of policies conductive \\
& to responsible alcohol service, and guidelines for assisting managers in administering the programme to \\
& servers in their own establishments.
\end{tabular}




\section{Characteristics of included studies (Continued)}

Control establishments were not exposed to the programme.

Outcomes

Knowledge and attitudes (in trained servers only), measued by questionnaire

Observed server behaviour (to pseudo-drunks)

Observed server behaviour (to 'real' patrons)

Notes

Allocation concealment $\quad$ D - Not used

Study

McLean 1994

Methods

Randomised trial, unit of allocation = bar.

Participants

Hobart, Tasmania; Australia

Experimental $=9$ bars

Control $=9$ bars

Interventions

Health promotion intervention

Distribution of '0.05 Know Your Limits' themed educational/promotional material, consistent with the immediate goal of preventing drink-driving.

Involved:

1) distribution of coasters advertising sensible drinking advice;

2) breath analyser placed in a prominent position and poster advertising its use;

3) stickers placed in toilets;

4) fact-sheets.

Outcomes Behaviour of patrons (alcohol consumption) measured using breath tests and interviews.

Notes

Allocation concealment $\mathrm{D}-$ Not used

\begin{tabular}{|c|c|}
\hline Study & Russ 1987 \\
\hline Methods & Non-randomised study, unit of allocation = server. \\
\hline Participants & $\begin{array}{l}\text { Rural university town, USA } \\
\text { Experimental = } 16 \text { servers } \\
\text { Control = } 9 \text { servers } \\
\text { Experimental and control servers from two taverns. }\end{array}$ \\
\hline Interventions & $\begin{array}{l}\text { Server training } \\
\text { Training for Intervention Procedures by Servers of Alcohol (TIPS), approximately six hours in length. During } \\
\text { the training, servers are given information on the physiological effects of alcohol that can help them identify } \\
\text { specific earning signs indicating when a customer is about to overindulge. Next, servers are taught a variety } \\
\text { of tactics for dealing with intoxicated customers or those who appear to be approaching their limits. Use } \\
\text { of role-plays and discussion. Participants must correctly achieve at least } 70 \% \text { in a written test in order to } \\
\text { become certified servers. } \\
\text { Control servers did not receive the training. }\end{array}$ \\
\hline$\overline{\text { Outcomes }}$ & $\begin{array}{l}\text { Observed server behaviour (using pseudo-patrons) } \\
\text { Exit BAC of pseudo-patrons. }\end{array}$ \\
\hline Notes & \\
\hline Allocation concealment & D - Not used \\
\hline
\end{tabular}

Study

Methods

Participants

\section{Saltz 1987}

Controlled before-and-after study, unit of allocation = bar.

Navy sites, USA

Experimental $=$ one bar 


\section{Characteristics of included studies (Continued)}

\begin{tabular}{ll} 
Control =one bar \\
\hline Interventions & $\begin{array}{l}\text { Server training } \\
\text { Development of new and revised management policies regarding the service of alcohol and an 18-hour } \\
\text { training course for all club personnel (five weekly sessions of 3-4 hours each). The training curriculum was } \\
\text { designed to embody the principles of server intervention and blend them with the new policies that employees } \\
\text { were going to follow. Training conducted during August and beginning of September 1985. }\end{array}$ \\
& Control received no intervention. \\
\hline Outcomes & Behaviour of patrons (self-reported alcohol consumption), by interview. \\
\hline Notes & \\
\hline Allocation concealment & D - Not used
\end{tabular}

\begin{tabular}{|c|c|}
\hline Study & Saltz 1997 \\
\hline Methods & Non-randomised study, unit of allocation = community. \\
\hline Participants & $\begin{array}{l}\text { USA (Northern California, southern California, South Carolina). } \\
\text { Experimental = } 3 \text { communities } \\
\text { Control = } 3 \text { communities } \\
\text { Pairs of communities located in Northern California, southern California, South Carolina. }\end{array}$ \\
\hline Interventions & $\begin{array}{l}\text { Server training } \\
\text { Community intervention, five components: } \\
\text { 1) community mobilisation; } \\
\text { 2) responsible beverage service; } \\
\text { 3) drinking and driving (law enforcement); } \\
\text { 4) underage drinking (reducing availability); } \\
\text { 5) alcohol access component. } \\
\text { The primary goal of the responsible beverage service component was to reduce the likelihood of customer } \\
\text { intoxication at licensed on-premise establishments through responsible beverage service practices. A second } \\
\text { goal was for licensees to prevent already intoxicated patrons from driving or engaging in other risky behaviour } \\
\text { when impaired. Emphasis was placed on the managers' responsibility. } \\
\text { Training; four hour programme for servers, five hours for managers. The underlying philosophy was that of } \\
\text { prevention (of intoxication and problems) rather than intervention (after a customer has become intoxicated } \\
\text { or is causing problems). }\end{array}$ \\
\hline$\overline{\text { Outcomes }}$ & $\begin{array}{l}\text { Self-reported server behaviour (telephone survey of random sample). } \\
\text { Observed server behaviour (using pseudo-drunks). } \\
\text { (a number of other outcomes were measured for the evaluation of this intervention; the data extracted for } \\
\text { this review were restricted to the outcomes for which could be attributed to the server training component). }\end{array}$ \\
\hline Notes & $\begin{array}{l}\text { Server training one of five strategies encompassing this community intervention. Injury data (traffic crashes) } \\
\text { were also collected, however not used in this review as it was not possible to attribute changes in this outcome } \\
\text { to the server training component of the intervention. }\end{array}$ \\
\hline Allocation concealment & D - Not used \\
\hline
\end{tabular}

\begin{tabular}{ll} 
Study & Toomey 2001 \\
\hline Methods & Non-randomised study, unit of allocation $=$ bar. \\
\hline Participants & Licensed bars in the USA. \\
& Experimental = 5 bars \\
& Control $=9$ bars \\
\hline
\end{tabular}

Interventions Server training

Five one-on-one consultations (each 1-2 hours) once a week, for owners and managers of bars. Aims:

1) develop and implement written establishment policies that encourage responsible alcohol sales; 
2) inform and discuss new alcohol policies with staff.

Intervention was tailored specifically to each establishment. The goal was to change those actions of alcohol establishments (sales to minors and sales to patrons already significantly impaired by alcohol) that can lead to death, injury and damage.

\begin{tabular}{ll}
\hline Outcomes & Observed server behaviour (using pseudo-drunks). \\
\hline Notes & \\
\hline Allocation concealment & D - Not used \\
\hline
\end{tabular}

\begin{tabular}{|c|c|}
\hline Study & Wallin 2002 \\
\hline Methods & Non-randomised study, unit of allocation = area. \\
\hline Participants & $\begin{array}{l}\text { Licensed premises in Stockholm, Sweden. } \\
\text { Experimental area = northern part of central Stockholm }(-550 \text { licensed premises). } \\
\text { Control area = southern part of central Stockholm }(-270 \text { licensed premises }) .\end{array}$ \\
\hline Interventions & $\begin{array}{l}\text { Server training } \\
\text { 'STAD project', a multi-component community alcohol prevention project initiated in 1996. Main cate- } \\
\text { gories: } \\
\text { 1) Community mobilisation; } \\
\text { 2) Two day responsible beverage service training course; } \\
\text { 3) Enforcement of existing alcohol regulations. } \\
\text { The server training course targeted restaurant owners, bartenders, servers and doormen. It covered the medical } \\
\text { effects of alcohol consumption, information about alcohol laws, server intervention training, other drugs } \\
\text { and group discussions. }\end{array}$ \\
\hline Outcomes & Observed server behaviour (using pseudo-drunks). \\
\hline$\overline{\text { Notes }}$ & $\begin{array}{l}\text { Injury data (police reported violence) were also collected, however not used in this review as it was not } \\
\text { possible to attribute changes in this outcome to the server training component of the intervention. }\end{array}$ \\
\hline Allocation concealment & D - Not used \\
\hline Study & Warburton 2000 \\
\hline Methods & Randomised trial, unit of randomisation = bar. \\
\hline Participants & $\begin{array}{l}\text { Bars in South Wales, West Midlands, West of England; UK. } \\
\text { Experimental group = } 30 \text { bars } \\
\text { Control = } 23 \text { bars }\end{array}$ \\
\hline Interventions & $\begin{array}{l}\text { Complete replacement of pint glasses; } \\
\text { Experimental = toughened glassware, } \\
\text { Control = annealed glassware. }\end{array}$ \\
\hline Outcomes & Injuries to bar staff, by self-complete questionnaire. \\
\hline \multicolumn{2}{|l|}{ Notes } \\
\hline Allocation concealment & D - Not used \\
\hline
\end{tabular}

\section{Characteristics of excluded studies}

\begin{tabular}{ll}
\hline Study & Reason for exclusion \\
\hline Boots 1994 & Uncontrolled before-after study. \\
\hline Boots 1999 & Uncontrolled before-after study. \\
\hline Brigham 1995 & Uncontrolled before-after study. \\
\hline $\begin{array}{l}\text { Interventions in the alcohol server setting for preventing injuries (Review) } \\
\text { Copyright } \odot 2008 \text { The Cochrane Collaboration. Published by John Wiley \& Sons, Ltd }\end{array}$
\end{tabular}




\section{Characteristics of excluded studies (Continued)}

Chikritzhs $2002 \quad$ Intervention not eligible (licensing restriction).

\begin{tabular}{ll}
\hline Hingson 1996 & Intervention did not involve the alcohol server setting. \\
\hline Hocking 1983 & Intervention not in the alcohol server setting. \\
\hline Homel 2004 & Uncontrolled before-after study. \\
\hline Licata 2002 & Uncontrolled before-after study. \\
\hline Maguire 2003 & Uncontrolled before-after study. \\
\hline McKnight 1994 & Intervention not eligible (enhanced enforcement of legislation). \\
\hline Norström 2003 & Intervention not eligible (licensing). \\
\hline Reilly 1998 & Uncontrolled before-after study. \\
\hline Simons-Morton 1997 & Uncontrolled before-after study. \\
\hline Wagenaar 1991 & Intervention not eligible (server liability). \\
\hline Wagenaar 2000 & Intervention not in the alcohol server setting. \\
\hline Wundersitz 2002 & Uncontrolled before-after study. \\
\hline
\end{tabular}

\section{A D D I T I O NAL TABLES}

\section{Table 01. Cochrane Injuries Group specialised register - search strategy}

(alcohol* OR beer* OR wine* OR liquor* OR spirit* OR drink* OR drunk* OR intoxicat*) AND (serve* OR serving OR pub OR pubs OR bar OR bars OR nightclub* OR restaurant* OR staff* OR shop* OR sell OR selling OR sale OR supply* OR supplier* OR supplied OR purchas* OR licens* OR licenc*)

\section{Table 02. CENTRAL - search strategy}

\section{\#1 ACCIDENTS}

\#2 WOUNDS AND INJURIES

\#3 CRIME

\#4 AUTOMOBILE DRIVING

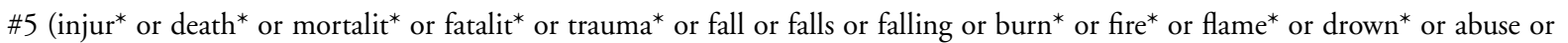

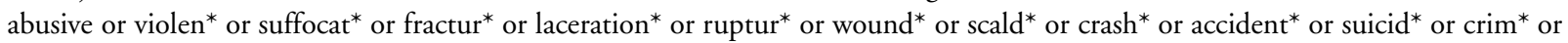
disorder* or offen* or assault* or murder* or homicid* or attack* or stab or stabbed or stabbing* or danger* or drunk* or driv* or impair* or convict* or arrest*:ti)

\#6 (injur* or death* or mortalit* or fatalit* or trauma* or fall or falls or falling or burn* or fire* or flame* or drown* or abuse or abusive or violen* or suffocat* or fractur* or laceration* or ruptur* or wound* or scald* or crash* or accident* or suicid* or crim* or disorder* or offen* or assault* or murder* or homicid* or attack* or stab or stabbed or stabbing* or danger* or drunk* or driv* or impair* or convict* or arrest*:ab)

\#7 (poison* near alcohol*)

$\# 8$ (\#1 or \#2 or \#3 or \#4 or \#5 or \#6 or \#7)

\#9ALCOHOL DRINKING

\#10 ALCOHOLIC BEVERAGES

\#11 ALCOHOLIC INTOXICATION

\#12 (alcohol* or beer* or wine* or liquor* ${ }^{*}$ or spirit ${ }^{*}$ or drink* or drunk* or intoxicat*:ti)

\#13 (alcohol* or beer* or wine* or liquor* or spirit* or drink* or drunk* or intoxicat*:ab)

\#14 (problem* next drink*)

\#15 (bing* near alcohol*)

Interventions in the alcohol server setting for preventing injuries (Review)

Copyright (c) 2008 The Cochrane Collaboration. Published by John Wiley \& Sons, Ltd 


\section{Table 02. CENTRAL - search strategy (Continued)}

\#16 (bing* near drink*)

$\# 17$ (\#9 or \#10 or \#11 or \#12 or \#13 or \#14 or \#15 or \#16)

\#18 (serve* or serving or pub or pubs or bar or bars or nightclub* or restaurant* or staff* or shop* or sell or selling or sale or supply* or supplier* or supplied or purchas* or licens* or licenc*:ti)

\#19 (serve* or serving or pub or pubs or bar or bars or nightclub* or restaurant* or staff* or shop* or sell or selling or sale or supply* or supplier* or supplied or purchas* or licens* or licenc*:ab)

\#20 ((industr* near alcohol) or (industr* near beer) or (industr* near brewery) or (industr* near liquor) or (industr* near wine))

\#21 (\#18 or \#19 or \#20)

\#22 (educat* or train* or promot* or interven* or program* or administer* or campaign* or evaluat* or assess* or compar* or prevent* or safe* or strateg* or scheme* or incentive* or trial* or environment*:ti)

\#23 (educat* or train* or promot* or interven* or program* or administer* or campaign* or evaluat* or assess* or compar* or prevent* or safe* or strateg* or scheme* or incentive* or trial* or environment*:ab)

\#24 (\#22 or \#23)

$\# 25$ (\#8 and \#17 and \#21 and \#24)

\#26 (\#25 and (not pregnan*))

\#27 (\#26 and (not anorexi*))

\#28 (\#27 and (not (drink* near water*)))

\section{Table 03. MEDLINE - search strategy}

\#1 explode accidents

\#2 explode wounds and injuries

\#3 explode crime

\#4 explode automobile driving

\#5 injur* OR death* OR mortalit* OR fatalit* OR trauma* OR fall OR falls OR falling OR burn* OR fire* OR flame* OR drown* OR abus* OR violen* OR suffocat* OR fractur* OR laceration* OR ruptur* OR wound* OR scald* OR crash* OR accident* OR suicid* OR crim* OR disorder* OR offen* OR assault* OR murder* OR homicid* OR attack* OR stab OR stabbed OR stabbing* OR danger* OR drunk* OR driv* OR impair* OR convict* OR arrest*

\#6 poison* near alcohol*

\#7 \#1 OR \#2 OR \#3 OR \#4 OR \#5 OR \#6

\#8 explode alcohol drinking

\#9 explode alcoholic beverages

\#10 explode alcoholic intoxication

\#11 alcohol* OR beer* OR wine* OR liquor* OR spirit* OR drink* OR drunk* OR intoxicat*

\#12 problem* near 1 drink* $^{*}$

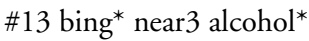

$\# 14$ bing* near1 drink*

\#15 \#7 OR \#8 OR \#9 OR \#10 OR \#11 OR \#12 OR \#13

\#16 serve* OR serving OR pub OR pubs OR bar OR bars OR nightclub* OR restaurant* OR staff* OR shop* OR sell OR selling OR sale OR supply* OR supplier* OR supplied OR purchas* OR licens* OR licenc*

\#17 industr* near (alcohol OR beer OR brewery OR liquor OR wine)

\#18\#16 OR \#17

\#19 explode intervention studies

\#20 educat* OR train* OR promot* OR interven* OR program* OR administer* OR campaign* OR evaluat* OR assess* OR control* OR compar* OR prevent* OR safe* OR strateg* OR scheme* OR incentive* OR trial* OR environment*

\#21 \#19 OR \#20

\#22 \#7 AND \#15 AND \#18 AND \#21

\#23 (tg=animals) NOT ((tg=human) and (tg=animals))

\#24 \#22 NOT \#23

Interventions in the alcohol server setting for preventing injuries (Review)

Copyright (c) 2008 The Cochrane Collaboration. Published by John Wiley \& Sons, Ltd 
Table 03. MEDLINE - search strategy (Continued)

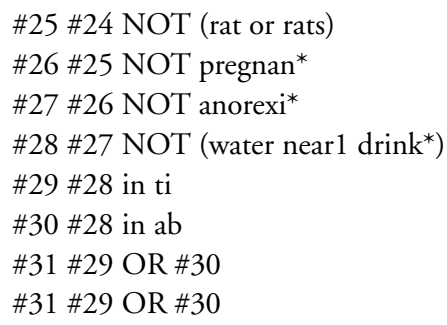

\section{Table 04. EMBASE - search strategy}

1 exp accidents/

2 exp injuries/

3 exp crimel

4 exp car driving/

5 (injur $\$$ or death $\$$ or mortalit $\$$ or fatalit $\$$ or trauma $\$$ or fall or falls or falling or burn\$ or fire $\$$ or flame $\$$ or drown $\$$ or abus $\$$ or violen $\$$ or suffocat $\$$ or fractur $\$$ or laceration $\$$ or ruptur $\$$ or wound $\$$ or scald $\$$ or crash $\$$ or accident $\$$ or suicid $\$$ or crim $\$$ or disorder $\$$ or offen $\$$ or assault $\$$ or murder $\$$ or homicid $\$$ or attack $\$$ or $\$ 0$ stab $\$ 1$ or stabbed or stabbing $\$$ or danger $\$$ or drunk $\$$ or driv $\$$ or impair\$ or convict\$ or arrest\$).ti,ab.

6 (poison $\$$ adj3 alcohol\$).mp.

71 or 2 or 3 or 4 or 5 or 6

8 exp alcohol drinking/

9 exp alcoholic beverages/

10 exp alcoholic intoxication/

11 (alcohol\$ or beer\$ or wine $\$$ or liquor $\$$ or spirit\$ or drink\$ or drunk\$ or intoxicat\$).ti,ab.

12 (problem\$ adj drink\$).mp.

13 (bing $\$$ adj3 alcohol\$).mp.

14 (bing\$ adj drink\$).mp.

158 or 9 or 10 or 11 or 12 or 13 or 14

16 ( $\$$ serve $\$ 1$ or $\$ 0$ serving or pub\$1 or bars $\$ 1$ or nightclub\$ or restaurant $\$$ or staff $\$$ or shop $\$$ or sell or selling or sale or supply $\$$ or supplier\$ or supplied or purchas\$ or licens\$ or licenc\$).ti,ab.

17 (industr\$ adj (alcohol or beer or brewery or liquor or wine)).mp.

1816 or 17

19 exp intervention studies/

20 (educat $\$$ or train $\$$ or promot $\$$ or interven $\$$ or program $\$$ or administer $\$$ or campaign $\$$ or evaluat $\$$ or assess $\$$ or control $\$$ or compar $\$$ or prevent $\$$ or safe $\$$ or strateg $\$$ or scheme $\$$ or incentive $\$$ or trial $\$$ or environment $\$$ ).ti,ab.

2119 or 20

227 and 15 and 18 and 21

2322 not (rat or rats).mp.

2423 not pregnan\$.mp.

2524 not anorexi\$.mp

2625 not (drink\$ adj2 water).mp.

\section{Table 05. PsycINFO - search strategy}

\#1 explode "Accidents-" in MJ,MN

\#2 explode "Injuries-" in MJ,MN

\#3 explode "Crime-" in MJ,MN

Interventions in the alcohol server setting for preventing injuries (Review) 


\section{Table 05. PsycINFO - search strategy (Continued)}

\#4 explode "Motor-Vehicles" in MJ,MN

\#5 injur* or death* or mortalit* or fatalit* or trauma* or fall or falls or falling or burn* or fire* or flame* or drown* or abus* or violen* or suffocat* or fractur* or laceration* or ruptur* or wound* or scald* or crash* or accident* or suicid* or crim* or disorder* or offen* or assault* or murder* or homicid* or attack* or stab or stabbed or stabbing* or danger* or drunk* or driv* or impair* or convict* or arrest*

\#6 poison* near alcohol*

$\# 7 \# 1$ or \#2 or \#3 or \#4 or \#5 or \#6

\#8 explode "Alcohol-Drinking-Attitudes" in MJ,MN

\#9 explode "Alcohol-Drinking-Patterns" in MJ,MN

\#10 explode "Alcohol-Intoxication" in MJ,MN

\#11 explode "Alcoholic-Beverages" in MJ,MN

\#12 alcohol* or beer* or wine* or liquor* or spirit* or drink* or drunk* or intoxicat*

\#13 problem* near 1 drink*

\#14 bing* near3 alcohol $^{*}$

\#15 bing* near1 drink*

$\# 16 \# 8$ or \#9 or \#10 or \#11 or \#12 or \#13 or \#14 or \#15

$\# 17$ serve* or serving or pub or pubs or bar or bars or nightclub* or restaurant* or staff* or shop* or sell or selling or sale or supply* or supplier* or supplied or purchas* or licens* or licenc*

\#18 industr* near (alcohol or beer or brewery or liquor or wine)

\#19 \#17 or \#18

\#20 educat* or train* or promot* or interven* or program* or administer* or campaign* or evaluat* or assess* or control* or compar* or prevent* or safe* $^{*}$ or strateg* or scheme* or incentive* or trial* or environment ${ }^{*}$

$\# 21$ \#7 and \#16 and \#19 and \#20

\#22 \#21 not pregnan*

\#23 \#24 not anorexi*

\#24 \#23 in ti

$\# 25 \# 23$ in ab

\#26 \#24 or \#25

\section{Table 06. SPECTR - search strategy}

\#1 $\left\{\right.$ alcohol*\} OR $\left\{\right.$ beer*\} OR $\left\{\right.$ wine $\left.^{*}\right\}$ OR $\left\{\right.$ liquor* \} OR $\left\{\right.$ spirit* $^{*}$ OR $\left\{\right.$ drink $\left.^{*}\right\}$ OR $\left\{\right.$ drunk $\left.^{*}\right\}$ OR $\{$ intoxicat* $\}$

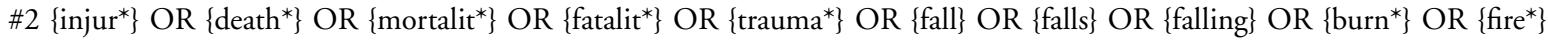

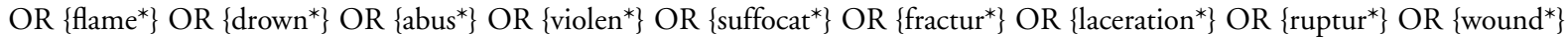

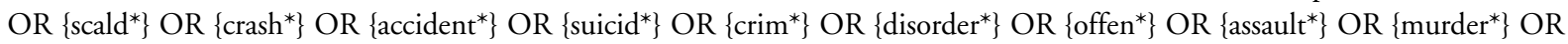
\{homicid*\} OR \{attack* OR $^{*}$ stab\} OR \{stabbed\} OR \{stabbing*\} OR \{danger*\} OR $\left\{\right.$ drunk $\left.^{*}\right\}$ OR $\left\{\right.$ driv $\left.^{*}\right\}$ OR $\left\{\right.$ impair $\left.^{*}\right\}$ OR $\left\{\right.$ convict* OR $\left\{\right.$ arrest* $\left.^{*}\right\}$

\#3 \#1 AND \#2

\section{Table 07. SIGLE - search strategy}

\#1 explode "Accidents-" / all SUBHEADINGS in MIME,MJME

\#2 explode " Wounds-and-Injuries" / all SUBHEADINGS in MIME,MJME

\#3 explode "Crime-" / all SUBHEADINGS in MIME,MJME

\#4 explode "Automobile-Driving" / all SUBHEADINGS in MIME,MJME

\#5 injur* or death* or mortalit* or fatalit* or trauma* or fall or falls or falling or burn* or fire* or flame* or drown* or abus* or violen* or suffocat* or fractur* or laceration* or ruptur* or wound* or scald* or crash* or accident* or suicid* or crim* or disorder* or offen* or assault* or murder* or homicid* or attack* or stab or stabbed or stabbing* or danger* or drunk* or driv* or impair* or convict* or 


\section{Table 07. SIGLE - search strategy (Continued)}

arrest*

\#6 poison* near alcohol*

$\# 7 \# 1$ or \#2 or \#3 or \#4 or \#5 or \#6

\#8 explode "Alcohol-Drinking" / all SUBHEADINGS in MIME,MJME

\#9 explode "“Alcoholic-Beverages" / all SUBHEADINGS in MIME,MJME

\#10 explode "Alcoholic-Intoxication” all SUBHEADINGS in MIME,MJME

\#11 alcohol* or beer* or wine* or liquor* or spirit* or drink* or drunk* or intoxicat*(4521 records)

\#12 problem* near1 drink*

\#13 bing* near3 alcohol*

\#14 bing* near1 drink*

$\# 15 \# 8$ or \#9 or \#10 or \#11 or \#12 or \#13 or \#14

\#16 serve* or serving or pub or pubs or bar or bars or nightclub* or restaurant* or staff* or shop* or sell or selling or sale or supply* or supplier* or supplied or purchas* or licens* or licenc*

\#17 industr* near (alcohol or beer or brewery or liquor or wine)

\#18 \#16 or \#17

\#19 educat* or train* or promot* or interven* or program* or administer* or campaign* or evaluat* or assess* or control* or compar* or prevent* or safe* $^{*}$ or strateg* or scheme* or incentive* or trial* $^{*}$ or environment

$\# 20$ \#7 and \#15 and \#18

\#21 \#19 or \#20

\section{Table 08. Methodological quality - allocation bias}

Boots 1995

Buka 1999

Casteel 2004

Felson 1997

Gliksman 1993

Graham 2004

Holder 1994

Howard-Pitney 1991 Non-randomised study, unit of allocation = bar.

Ninety-seven servers from 26 different establishments attended training were used as the intervention group.

Non-randomised, unit of allocation $=$ town.

The experimental town (Geelong) was assigned to the intervention as it was at high risk for alcohol-related problems. The control town (Bunbury) was selected on the basis of being of a similar size to the experimental town.

Randomised trial, unit of allocation = community.

Three communities, one of which was reported as being selected at random to be the experimental site and the remaining two sites were used as controls. Allocation concealment was not reported.

Controlled before-and-after, unit of allocation = liquor stores.

After invitation to participate in the study, stores that agreed were used as the experimental group; those that refused were used as the control group.

Controlled before-and-after, unit of allocation $=$ area.

The experimental city was chosen in response to a 'pub-hopping' and associated crime problem. The metropolitan area of six other cities from the same state, used as the control.

Randomised study, unit of allocation = bar.

Four pairs of matched bars; one bar from each pair was randomly selected to receive the intervention, no further details are presented.

Randomised trial, unit of allocation $=$ bar.

26 bars were randomly assigned by drawing lots to receive the intervention, the remaining served as controls. Allocation concealment was poor.

Controlled before-and-after, unit of allocation = US state.

US state of Oregon which had introduced a mandated responsible server training policy (in December 1986) acted as the experimental site with data from other 47 US states used as control.

Interventions in the alcohol server setting for preventing injuries (Review) 


\section{Table 08. Methodological quality - allocation bias (Continued)}

Johnsson 2003

Krass 1994

Lacey 2000

Lang 1998

McKnight 1991

McLean 1994

Russ 1987

Saltz 1987

Saltz 1997

Toomey 2001

Wallin 2003

Warburton 2000
Control premises $(\mathrm{n}=14)$ were 'randomly selected'.

Randomised trial, unit of allocation $=$ bars.

Randomisation was stratified for number of members of each bar. Six of 12 student bars at Lund University were allocated by drawing lots to the intervention group, remaining six were used as the control group.

Randomised study, unit of allocation =bar.

Eight premises agreed to participate. The bars were matched into pairs and then one from each pair was assigned at random to the experimental group.

Controlled before-and-after, unit of allocation $=$ area.

Since 1983 Pitney County, Colorado has had a 'Tipsy Taxi' service. Two nearby comparison jurisdictions were used as controls.

Non-randomised, unit of allocation=bar.

Seven out of 50 bars which were eligible and agreed to participate were used as the experimental group. Seven control bars were then selected.

Non-randomised, unit of allocation $=$ bar.

100 premises comprised the experimental group and 138 premises were used as control.

Randomised trial, unit of allocation = bar.

Eighteen 'hotels' in Hobart, were randomly allocated to experimental $(n=9)$ or control groups $(n=9)$ using a table of random numbers method. Allocation concealment was poor.

Non-randomised, unit of allocation=server

Seventeen servers employed at two local taverns participated. $50 \%$ of serving staff at each bar attended training, reasons for non-participation included lack of interest and inability to attend the training. The remaining untrained servers were used as the controls.

Non-randomised, unit of allocation=bar.

Two US Navy clubs were selected, one control and one experimental.

Non-randomised, unit of allocation=community.

Three community pairs were selected; three experimental and three matched comparison communities.

Non-randomised, unit of allocation $=$ bar.

Five experimental bars, each with two matched control bars.

Non-randomised, unit of allocation $=$ area .

Experimental area comprised the northern part of central Stockholm (containing -550 licensed premises) and control comprised the southern part of central Stockholm (containing - 270 licensed premises).

Randomised trial, unit of allocation=bars.

53 bars were randomly assigned to experimental ( $n=30$, toughened glassware) and control $(n=30$, annealed glassware) groups. Method of randomisation was not reported.

\section{Table 09. Methodological quality -confounders}

Boots 1995 Geelong was reported as having a high rate of per capita drinking, drink driving charges, alcohol-related hospital admission, alcohol-related injuries and alcohol consumption occurring in the private setting.

Buka 1999 The communities were reported as being similar in regard to vital statistics, hospital discharge data and police statistics on motor vehicle crashes and arrests. The communities were of comparable size, sociodemographic characteristics, prevalence of alcohol-related problems and levels of institutional development and community organisation.

Casteel $2004 \quad$ Control stores were reported as being located in higher crime areas than experimental, no other information

Interventions in the alcohol server setting for preventing injuries (Review) 


\title{
Table 09. Methodological quality -confounders (Continued)
}

\author{
given.
}

Felson 1997

The pre-intervention serious assault rate was higher in the intervention area; rate per 100,000 population, was 117 for the experimental city and 77 for the control.

Gliksman 1993 The premises were chosen to represent four types of establishment; each type represented by two bars, matched on type of liquor licence, characteristics of clientele, location, volume of business and atmosphere.

Graham $2004 \quad$ Prior to assignment, bars were stratified according to location, type, size plus ethnicity and age of patrons.

Holder $1994 \quad$ Not reported.

Howard-Pitney 1991 Control premises were matched on premise type and size. Any differences at baseline between the groups were not reported.

Johnsson 2003 Any differences in baseline between the groups were not reported.

Krass 1994 Bars were matched in pairs according to size and type of clientele prior to intervention assignment.

Lacey $2000 \quad$ Comparison jurisdictions had similar socio-economic status and DUI enforcement systems to the experimental area.

Lang 1998 The control bars were each selected to match one of the experimental bars according to risk status, licence type and total alcohol purchases.

McKnight 1991 The control premises were matched according to size and characteristics to experimental premises.

McLean $1994 \quad$ Reported as being no difference.

Russ 1987 Any differences in baseline characteristics between the two groups are not reported.

Saltz 1987 The control was selected for its operation similarity and geographical proximity to the experimental club.

Saltz 1997 Each control community was reported as being 'matched' to an experimental community on the basis of similar local geographic area characteristics, similar industrial/agricultural bases and minority compositions.

Toomey $2001 \quad$ Bars were matched according to bar type and location.

Wallin $2003 \quad$ Any differences in baseline characteristics between the two areas are not reported.

Warburton $2000 \quad$ Any differences in baseline characteristics between the two groups are not reported.

\section{Table 10. Methodological quality - blinding}

Boots $1995 \quad$ Not reported.

Buka $1999 \quad$ Not reported.

Casteel $2004 \quad$ Outcome data were obtained from the Crime Analysis Unit of the Santa Monica Police Department.

Felson 1997 Serious assault data were obtained from police reports (NB the police took a lead in implementing intervention).

Gliksman $1993 \quad$ Pseudo-drunks and observers were blind to allocation status.

Graham $2004 \quad$ Observers were blind to allocation status of the bar. Control bars were unaware of their allocation status.

Holder 1994 Crash data were obtained from the Oregon Highway Division and the Fatal Accident Reporting system of the US Department of Transport. 


\section{Table 10. Methodological quality - blinding (Continued)}

Howard-Pitney 1991 The observers were blind to allocation status and the servers were unaware that they were being observed.

Johnsson $2003 \quad$ Those conducting the breath tests were not aware of allocation status.

Krass $1994 \quad$ Interviewers were blind to allocation status.

Lacey $2000 \quad$ Not reported.

Lang 1998 Research assistants and pseudo-patrons were not informed of the design of the study or allocation status. Drink driving data were obtained from police reports.

McKnight 1991 Observers were blind to allocation status and servers were not informed that observation would occur.

McLean 1994 Investigators were aware of the allocation status of the bars. The control bars, however, were not informed of their status.

Russ 1987 Pseudo-drunks were blinded to allocation status.

Saltz $1987 \quad$ Not reported.

Saltz $1997 \quad$ Not reported.

Toomey $2001 \quad$ Bars were unaware of the observation and the pseudo-drunks were blind to allocation status.

Wallin $2003 \quad$ Pseudo-drunks were blind to allocation status.

Warburton $2000 \quad$ Bars did not know which glassware they were assigned to and researchers were blinded to allocation status.

\section{Table 11. Methodological quality - data collection methods}

Boots $1995 \quad$ Knowledge and behaviour data were collected by random telephone interviews. Response rate in experimental and control area were $63 \%$ and $56 \%$ respectively.

Buka 1999 Self-reported server behaviour was measured by questionnaire. From a sample of 25 premises from each control site and 50 experimental premises, three servers were randomly selected to complete the questionnaire. Response rates for questionnaires was $68 \%$ in the experimental area (31\% of these were from trained servers), $72 \%$ in control $\mathrm{A}$ and $63 \%$ in control $\mathrm{B}$.

Casteel $2004 \quad$ Extracted from police records.

Felson $1997 \quad$ Extracted from police records.

Gliksman $1993 \quad$ 1) Knowledge and attitudes were measured, in the trained servers only, by questionnaires. The knowledge questionnaire was completed for 55/57 and the attitudes questionnaire completed for 57/57.

2) Observations of server behaviour using pseudo-drunks were conducted with trained actors and observers on standardised days and times using standardised forms.

Graham $2004 \quad$ Data were obtained from 734 pre and post observations were made by paired of trained observers. Agreement among raters found to be generally high.

Holder $1994 \quad$ Extracted from official records.

Howard-Pitney 1991 Knowledge was assessed in trained servers only using a questionnaire before and after training. Server behaviour was measured by pairs of trained observers. Observations were made in 13 of 21 establishments with trained managers and 11 of 14 control premises.

Johnsson $2003 \quad$ Patron intoxication was measured at baseline and one month after intervention, by breath test in invited and consenting patrons. 664 tests were made at baseline, one patron refused. 658 tests were made at follow-up (360 in experimental, 298 in control), there were no refusals. 


\section{Table 11. Methodological quality - data collection methods (Continued)}

Krass $1994 \quad$ Knowledge was measured in the trained servers only using pre and post questionnaire, 66 completed. Exit surveys of a sample of patrons involving a breath test and interview. 233 pre-test patron interviews were made at five sites (response rate=40\%), 305 post-test interviews at four sites (response rate $=53 \%$ ). Observed estimates of BAC of patrons who refused to participate were made to assess volunteer bias.

Knowledge was measured in the trained servers only using pre and post questionnaire, 66 completed. Exit surveys of a sample of patrons involving a breath test and interview. 233 pre-test patron interviews were made at five sites (response rate $=40 \%$ ), 305 post-test interviews at four sites (response rate $=53 \%$ ). Observed estimates of BAC of patrons who refused to participate were made to assess volunteer bias.

Knowledge was measured in the trained servers only using pre and post questionnaire, 66 completed.

Exit surveys of a sample of patrons involving a breath test and interview. 233 pre-test patron interviews were made at five sites (response rate=40\%), 305 post-test interviews at four sites (response rate $=53 \%$ ). Observed estimates of BAC of patrons who refused to participate were made to assess volunteer bias.

Knowledge was measured in the trained servers only using pre and post questionnaire, 66 completed.

Exit surveys of a sample of patrons involving a breath test and interview. 233 pre-test patron interviews were made at five sites (response rate $=40 \%$ ), 305 post-test interviews at four sites (response rate $=53 \%$ ). Observed estimates of BAC of patrons who refused to participate were made to assess volunteer bias.

Knowledge was measured in the trained servers only using pre and post questionnaire, 66 completed.

Exit surveys of a sample of patrons involving a breath test and interview. 233 pre-test patron interviews were made at five sites (response rate $=40 \%$ ), 305 post-test interviews at four sites (response rate $=53 \%$ ). Observed estimates of BAC of patrons who refused to participate were made to assess volunteer bias.

Lacey 2000 Not reported.

Lang 1998

Knowledge questionnaire, $56.9 \%$ of the trained servers completed the follow-up questionnaire. Observations of server behaviour using actors as pseudo-drunks made at each site pre and post intervention, total of 78 visits made.

Drink driving data were extracted from official records.

Patron interviews, overall $2375 / 3191$ of patrons consented to be surveyed (74.4\%). For refusals an observed assessment of drunkenness was recorded.

McKnight $1991 \quad$ Knowledge was measured in the trained servers by questionnaire. Response rates to questionnaire varied between 51 and $83 \%$

Three/four observations of server behaviour to pseudo-drunks made in each premise before and after

McLean 1994

Russ 1987

Patrons were 'randomly' approached to be interviewed and breath tested.

Observations used to assess server behaviour; 49 visits ( 24 before and 25 after) were made and interaction with server was tape recorded.

Saltz 1987 Random patron interviews were used to gather outcome data.

Saltz 1997 Managers' attitudes and behaviour were assessed by telephone survey of a random sample.

Pseudo-patron survey 65 and 67 experimental premises visited at baseline and follow-up and 67 and 69 control premises visited, respectively.

Toomey $2001 \quad$ Observed server behaviour using pseudo-drunks.

Wallin 2003 Observations of server behaviour to pseudo-drunks used to assess server behaviour. At follow-up 103 premises were visited, 42 in control and 61 in intervention.

Violence data were collected from police records for 48 months before and 33 months after.

Warburton $2000 \quad$ Injury data were collected over six months, by self-completed questionnaire (distributed through bar managers), response rate is unknown.

Interventions in the alcohol server setting for preventing injuries (Review) 


\section{Table 12. Methodological quality - withdrawals \& dropouts}

\begin{tabular}{|c|c|}
\hline Boots 1995 & $\mathrm{~N} / \mathrm{A}$ \\
\hline Buka 1999 & $\mathrm{~N} / \mathrm{A}$ \\
\hline Casteel 2004 & None reported. \\
\hline Felson 1997 & N/A \\
\hline Gliksman 1993 & None reported. \\
\hline Graham 2004 & Eight bars dropped out after assignment to experimental group and were not included in the analysis. \\
\hline Holder 1994 & N/A \\
\hline Howard-Pitney 1991 & None reported. \\
\hline Johnsson 2003 & None reported. \\
\hline Krass 1994 & Three bars withdrew from the baseline patron exit surveys and four withdrew from the follow-up surveys. \\
\hline Lacey 2000 & N/A \\
\hline Lang 1998 & One experimental bar refused to participate in the patron exit surveys. \\
\hline McKnight 1991 & None reported. \\
\hline McLean 1991 & Two control bars withdrew from the patron surveys. \\
\hline Russ 1987 & None reported. \\
\hline Saltz 1987 & N/A \\
\hline Saltz 1997 & $\mathrm{~N} / \mathrm{A}$ \\
\hline Toomey 2001 & $\begin{array}{l}\text { One control premise was dropped from the study, therefore analysis based on five experimental and nine } \\
\text { control bars. }\end{array}$ \\
\hline Wallin 2003 & N/A \\
\hline Warburton 2000 & $\begin{array}{l}\text { Four bars did not receive their allocated intervention and were excluded from the analysis. Nine bars in } \\
\text { control and } 14 \text { in experimental were lost to follow-up. }\end{array}$ \\
\hline
\end{tabular}

\section{Table 13. Methodological quality - intervention integrity}

Boots 1995 10/11 licensed takeaway premises in the experimental area participated, but it is reported that the 'level of implementation varied'.

Buka 1999 Of 531 servers in the experimental community, 324 (61\%) completed the intervention.

Casteel 2004 It is reported that there was variation in the extent to which experimental stores complied with the intervention.

Felson $1997 \quad$ Compliance with intervention is not reported.

Gliksman $1993 \quad 57$ servers in the experimental group received trained.

Graham $2004 \quad$ Participation rate in the training was $84 \%$ of staff.

Holder $1994 \quad$ N/A

Interventions in the alcohol server setting for preventing injuries (Review) 


\section{Table 13. Methodological quality - intervention integrity (Continued)}

Howard-Pitney 1991 Not reported.

Johnsson $2003 \quad$ Forty staff in 'key positions' from experimental bars were trained.

Krass $1994 \quad 70$ servers were trained.

Lacey $2000 \quad$ N/A

Lang $1998 \quad 61 \%$ of available servers were trained, at follow-up 25 of trained servers had left their job.

McKnight $1991 \quad 1079$ servers were trained.

McLean $1994 \quad$ Compliance with intervention varied.

Russ 1987

All experimental servers completed training.

Saltz 1987

Not reported.

Saltz 1997

In the experimental communities there were 240 premises, 141 were targeted for training of which 72 (51\%) attended with 276 staff trained.

Toomey $2001 \quad$ Full compliance is reported, which for this study was one bar owner/manager from each experimental bar receiving training.

Wallin $2003 \quad 37$ of the 61experimental bars sampled had trained their staff.

Warburton $2000 \quad$ Whole stock of pint glassware was replaced.

\section{Table 14. Methodological quality - follow-up}

Boots 1995 Length of the data collection period is not reported.

Buka $1999 \quad$ Data were collected four years after intervention.

Casteel 2004 Data were collected for 4.5 years before and 2 years after intervention implementation.

Felson 1997 Data collection periods were one year pre and four years post-intervention.

Gliksman $1993 \quad$ 1) Knowledge and attitudes were measured immediately before and after the intervention.

2) Observations were made in all eight bars two weeks before and after the intervention.

Graham $2004 \quad$ Observations were made six months before and after intervention.

The percentage of staff that received training and were still employed at the same bar varied from $18.5 \%$ to $100 \%$ (mean 61.2\%).

Holder 1994 Crash data were collected for 11 years before and two years after introduction of the policy.

Howard-Pitney 1991 Length of before and after periods of administration of knowledge questionnaire was not stated. Observations took place 4-6 weeks after intervention.

Johnsson $2003 \quad$ Follow-up data were collected one month after intervention.

Krass $1994 \quad$ Knowledge questionnaire administered immediately before and after training. Patron exits surveys were conducted four weeks after intervention.

Lacey 2000

Crash data collected for the period 1976-1998 (7 years before and 15 year after intervention).

Lang 1998

Knowledge questionnaires were administered before and three months after intervention.

Observations of server behaviour were made before (length of pre-test period not stated) and three months after intervention. 
Table 14. Methodological quality - follow-up (Continued)

Drink driving data were collected for nine months before and three months after training.

Patron behaviour through interviews.

McKnight $1991 \quad$ Length of study period for the server observation was not reported.

McLean 1994 Intervention was implemented on the Monday of the trial week and follow-up surveys made on the following Thursday, Friday and Saturday evenings. Response rates to the patron survey were $61 \%$ and $66 \%$ in experimental and control, respectively.

Russ 1987

Study period over 11 weeks.

Saltz $1987 \quad$ Patrons were selected randomly; response rates 90\% in experimental premises for both pre and post test and $90 \%$ and $87 \%$ in control respectively.

Pre and post intervention periods were 4-6 weeks in length.

Saltz $1997 \quad$ Response rates of survey ranged from 60-69\% and 55-67\% for the experimental communities at the pre and post periods, and 55-62\% and 54-66\% in the control, respectively. Measurements at baseline and at 'early stages' of the programme.

Pseudo-patron surveys were carried out at baseline and 3-5 months after.

Toomey $2001 \quad$ Pseudo-drunks used to assess server behaviour 4-6 weeks after intervention.

Wallin 2003 Observations conducted at the start of the intervention (1996) and three years after intervention (1999).

Warburton $2000 \quad$ Total of 1229 (653 experimental and 576 control) questionnaires were completed and returned.

\section{Table 15. Results - server training (injuries)}

$\begin{array}{ll}\text { Buka 1999 } & \text { Not measured. } \\ \text { Gliksman 1993 } & \text { Not measured. } \\ \text { Graham 2004 } & \text { Not measured. } \\ \text { Holder 1994 } & \text { SINGLE VEHI } \\ & \begin{array}{l}\text { Effect estimate } \\ \text { The estimate is } \\ \text { legislation and r }\end{array} \\ & \begin{array}{l}\text { Authors report } \\ \text { 4\% after six mont }\end{array} \\ \text { Howard-Pitney 1991 } & \text { Not measured. } \\ \text { Johnsson 2003 } & \text { Not measured. } \\ \text { Krass 1994 } & \text { Not measured. } \\ \text { Lang 1998 } & \text { Not measured. } \\ \text { McKnight 1991 } & \text { Not measured. } \\ \text { Russ 1987 } & \text { Not measured. } \\ \text { Saltz 1987 } & \text { Not measured. } \\ \text { Saltz 1997 } & \text { Not measured. } \\ \text { Toomey 2001 } & \text { Not measured. }\end{array}$


Table 15. Results - server training (injuries) (Continued)

Wallin 2003

POLICE REPORTED VIOLENCE

When adjusting for the development in the control area, the intervention parameter $=-0.344(\mathrm{se}=0.046)$, $\mathrm{P}<0.001$. The authors estimated this to represent a $29 \%$ reduction in police-reported violence in the experimental area. 


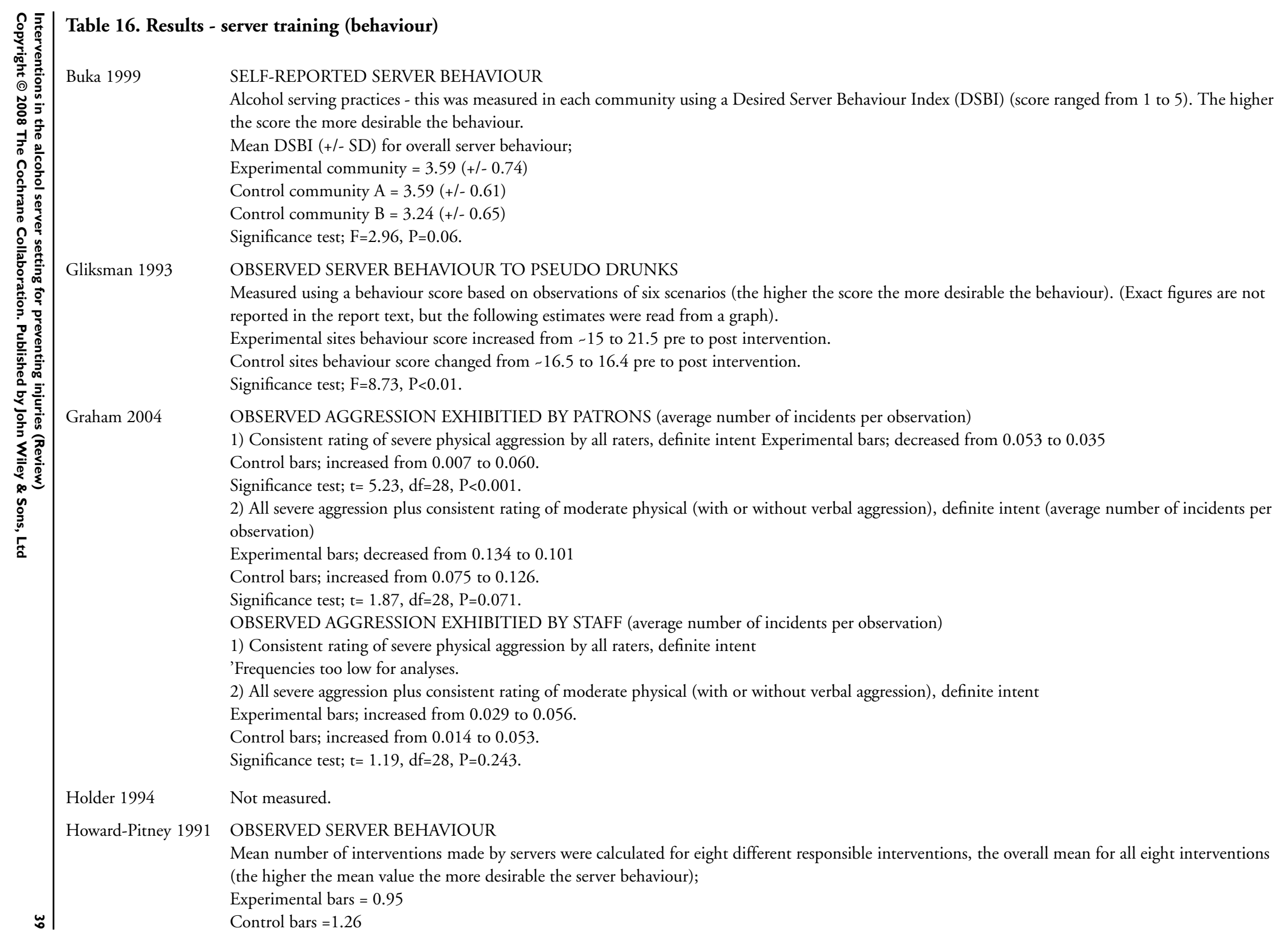


Confidence intervals and results of significance test are not presented however, the authors report that 'no differences were observed between treatment and control servers on any intervention or on a sum average of eight possible interventions'.

\section{BEHAVIOUR OF PATRONS}

Change in $\mathrm{BAC}(\mathrm{mg} \%)$ (and 95\% CIs) between baseline and follow-up;

Experimental bars $=-0.004 \%(-0.012$ to 0.004$)$

Control bars $=+0.007 \%(-0.001$ to 0.015$)$.

Mean difference in BAC between experimental and control bars $=-0.011 \%$ (95\% CI 0.022 to 0.000$)$.

In the experimental group $40 \%$ of tested patrons had a BAC greater than $0.1 \%$ before the training and $39 \%$ after. In the control group the corresponding figures were $34 \%$ before and $41 \%$ after. The difference between these changes was not significant ( $\mathrm{P}=0.12$, one-tailed, $95 \% \mathrm{CI}-0.45$ to 1.10 ).

\section{BEHAVIOUR OF PATRONS}

1) Mean BAC (mg\%) of patrons

This increased from 0.055 ( $95 \%$ CI 0.049 to 0.065 ) to 0.069 (95\% CI 0.058 to 0.078 ) over the study period in the experimental sites, and increased from 0.057 (95\% CI 0.050 to 0.078 ) to 0.058 (95\% CI 0.050 to 0.066 ).

2) Total consumption of alcohol (gm)

On experimental premises this increased from 62.4 (95\% CI 50.5 to 74.4 ) to 69.3 (95\% CI 56.9 to 81.6 ), and decreased from 79.0 (95\% CI 82.9 to 95.1) to 67.9 (95\% CI 56.7 to 79.1 ) in control premises.

The authors report that 'no significant differences were found in mean BAC and total consumption of alcohol between experimental and control sites at pre and post level'.

3) Proportion of patrons with a BAC over $0.10 \mathrm{mg} \%$

This increased from $-0.17 \%$ to $-0.27 \%$ in intervention sites and reduced from $-0.23 \%$ to $0.2 \%$ in the control sites (exact figures are not presented in the report text, but the following estimates were read from a graph). No confidence intervals or significance test results presented for this outcome.

\section{BEHAVIOUR OF PATRONS}

1) Drink driving offences

No quantitative data presented. The authors report that 'the downward trend in drink driving offences from intervention premises leading up to the project was continued during the evaluation period, while the figure for the control sites remained relatively unchanged. However, the number of drink driving cases from both intervention and control premises were too few to permit any meaningful evaluation'.

2) Percentage of tested patrons with a $\operatorname{BAL}(\mathrm{mg} \%)>0.15$

This reduced over the study period, with the decline greater for experimental sites (17.4\% to $5.3 \%)$ than control (10.1 to $3.7 \%)$, this is not significant $(\mathrm{P}=0.389)$.

3) Percentage of tested patrons with a BAL $>0.08$

This decreased from $52 \%$ to $26.9 \%$ in experimental sites and decreased from $34.8 \%$ to $24 \%$, this rate of decline is significantly greater $(\mathrm{P}<0.029)$ for the experimental than for the control group.

SELF-REPORTED SERVER BEHAVIOUR

Changes in the average ratings in mean score of the adoption of responsible service policies over the pre and post periods were reported as not statistically significant (full results of significance test is not presented). Total score increased from -0.7 to 0.9 in intervention sites and remained unchanged at -1.8 in control sites (maximum possible score $=+2$, minimum possible score $=-2$ ). 


\section{OBSERVED SERVER BEHAVIOUR}

Reported that there was no difference between experimental and control in terms of refusal of service to intoxicated pseudos.

In the experimental group, 1 out of 11 visits and 3 out of 14 visits were refused service in the pre and post period respectively. In the control group, 1 out of 14 visits were refused service in both the pre and post period. Authors report that 'no further analyses were undertaken'.

\section{SELF-REPORTED SERVER BEHAVIOUR (trained servers only)}

1) Serving practices, mean score $(+/$-sd);

Pre $=3.13(+/-0.67)$

Post $=3.50(+/-0.68)$

Significance test; $\operatorname{diff}=0.57, \mathrm{t}=11.90, \mathrm{P}<0.01$

2) Serving policies mean score $(+/-s d)$;

Pre $=0.58(+/-0.12)$

Post $=0.65(+/-0.11)$

Significance test; $\operatorname{diff}=0.61, \mathrm{t}=6.65, \mathrm{P}<0.01$

OBSERVED SERVER BEHAVIOUR

1) Percentage change between pre and post server 'intervention level':

a) Intervention level = 'None' (servers make no attempt to intervene);

Experimental $=-12.5 \%$

Control $=-0.8 \%$

b) Intervention level = 'Partial' (servers provide drink requested but make some attempt at intervention);

Experimental $=+10.5 \%$

Control $=+1.7 \%$

c) Intervention level = 'Full' (servers refuse to serve any alcoholic beverage);

Experimental $=+1.9 \%$

Control $=-0.7 \%$

2) Mean score of server intervention (the higher the score the more desirable);

Mean score in experimental sites increased from 0.19 to 0.34 (diff $=0.15, \mathrm{~F}=10.42, \mathrm{P}<0.01)$ between the pre and post periods. Mean score in control sites remained at 0.22 (diff $=0.00, \mathrm{~F}=0.01, \mathrm{P}=0.97$ ) between the pre and post periods.

Significance test of the difference between the intervention effects in the experimental and control sites; $\mathrm{F}=6.70, \mathrm{df}=1 / 207, \mathrm{P}=0.01$ ).

OBSERVED 'REAL' PATRON INTOXICATION

Amongst the experimental sites the mean intervention level increased from 0.03 before, to 0.22 after $(\mathrm{F}=4.27, \mathrm{df}=1 / 127, \mathrm{P}=0.04)$, for the comparison sites remained unchanged at $0.07(\mathrm{~F}=0.87, \mathrm{df}=1 / 167, \mathrm{P}=0.35)$ across the periods.

\section{OBSERVED SERVER BEHAVIOUR}

Trained servers on average were reported as attempting a greater frequency of intervention than servers without training $(\mathrm{P}<0.05)$.

BEHAVIOUR OF PATRONS

The average exit $\mathrm{BAC}(\% \mathrm{mg})$ for pseudo patrons served by servers who remained untrained was $0.103(+/-0.033)$, while those served by trained personnel had an average BAC of $0.059(+/-0.019)$ 


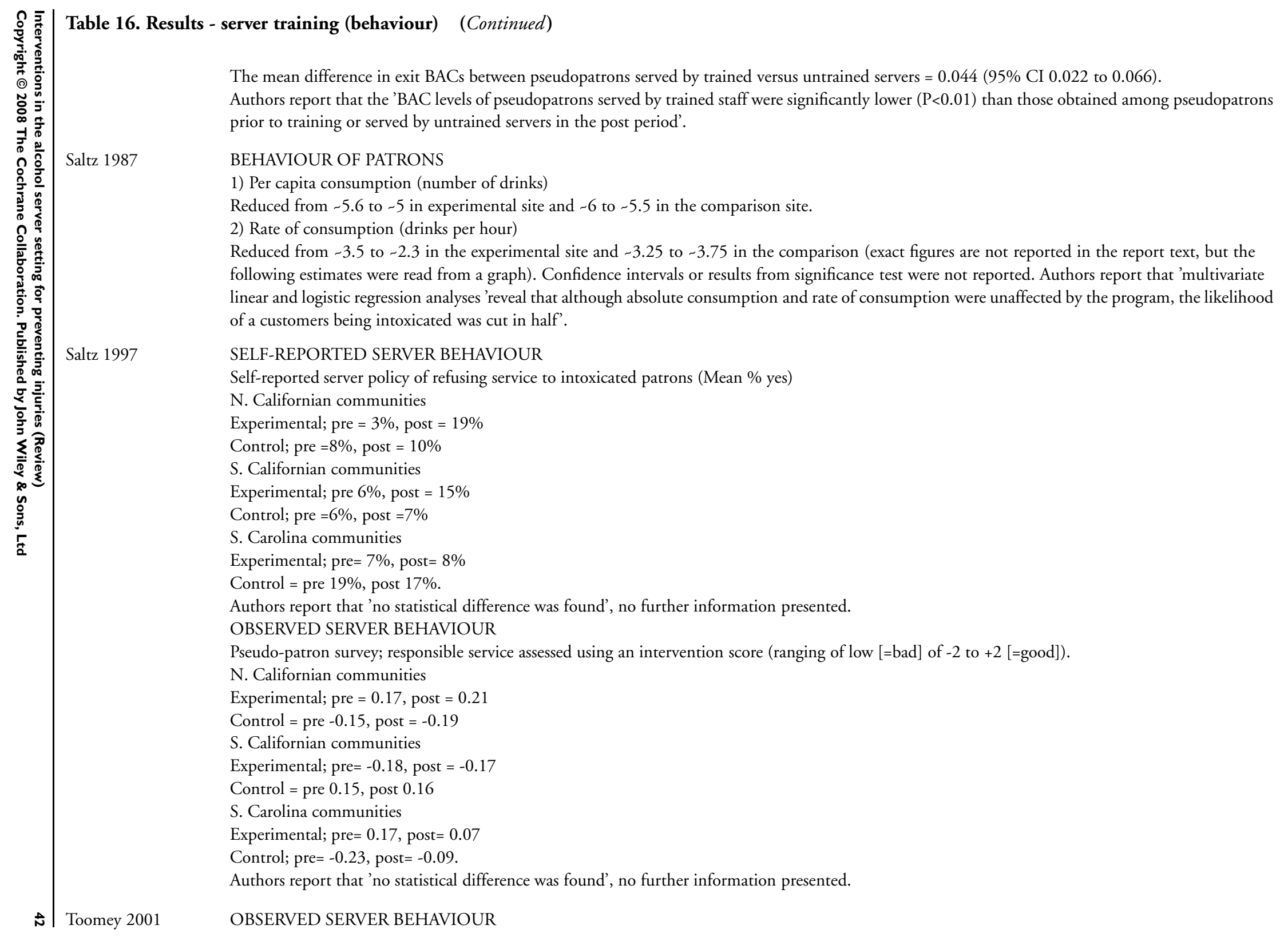




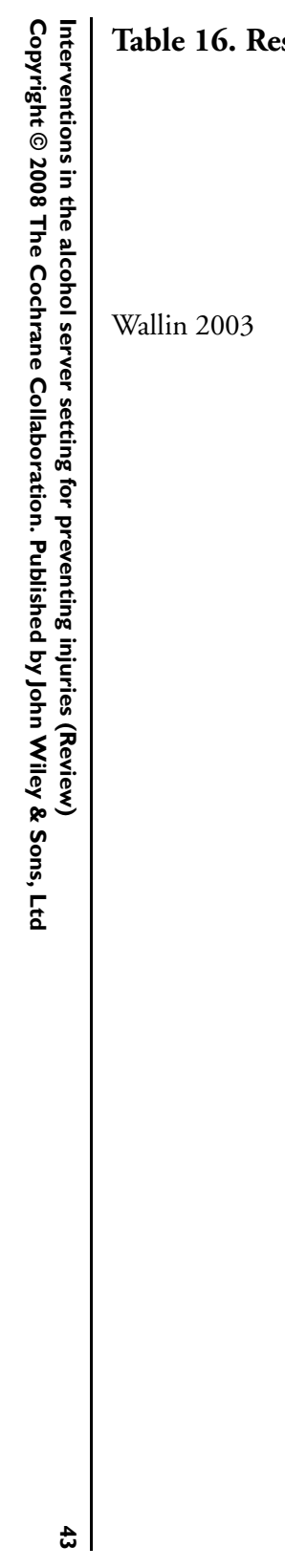

Pre-intervention, the purchase rates were $68.4 \%$ and $70.1 \%$, in the experimental and control sites respectively. Post-intervention, the purchase rate reduced in the intervention site to $40.0 \%$ and increased to $72.9 \%$ in the control. The relative decline was reported as not statistically significant $(\mathrm{t}=-$ $1.17, \mathrm{P}=0.27$ ).

Refusal of service to pseudo-intoxicated patrons changed from $83.1 \%$ to $80.3 \%$ in experimental and from $63.0 \%$ to $54.8 \%$ in control ( $\mathrm{t}=0.24$, $\mathrm{P}=0.81$ ). OBSERVED SERVER BEHAVIOUR

Refusal rates to intoxicated patrons was $55 \%$ in the experimental sites which had received training, $48 \%$ in intervention sites yet to be receive training, and $38 \%$ in the control area. The authors reported that this was not significant, no further details presented. 


\title{
Table 17. Results - server training (knowledge)
}

\author{
Buka $1999 \quad$ Not measured. \\ Gliksman $1993 \quad$ KNOWLEDGE OF SERVERS \\ This was measured in the trained servers only. \\ Results for the true/false section increased significantly pre to post test, $\mathrm{t}=-12.5, \mathrm{P}<0.001$. \\ Results for the open-ended question section increased significantly pre to post test, mean score increased from \\ 1.3 to $5.29, \mathrm{t}=-10.89, \mathrm{P}<0.001$. \\ Graham $2004 \quad$ Not measured. \\ Holder $1994 \quad$ Not measured. \\ Howard-Pitney 1991 KNOWLEDGE OF SERVERS \\ This was measured in trained group only. Formal measures of effect and confidence intervals are not presented \\ however, the authors report that servers and managers increased their knowledge and showed improvement in \\ their beliefs that customers would respond favourably to responsible alcohol service and policies $\mathrm{P}<0.001$, all \\ measures'. \\ Johnsson $2003 \quad$ Not measured. \\ Krass $1994 \quad$ KNOWLEDGE OF SERVERS \\ This was measured in trained group only. Mean total knowledge score increased from 23.98 to 30.8; $\mathrm{t}=$ - \\ $12.03, \mathrm{df}=66, \mathrm{P}<0.001$. \\ Lang $1998 \quad$ KNOWLEDGE OF SERVERS \\ This was measured in trained group only. \\ The authors report a 'statistically significant $(>0.05)$ increase in knowledge of laws regarding serving obviously \\ drunk customers, maintained at follow-up. Overall, however, there were only minor increases in knowledge, \\ most of which was not retained at follow-up'. No other quantitative data is reported. \\ McKnight $1991 \quad$ Not measured. \\ Russ $1987 \quad$ Not measured. \\ Saltz $1987 \quad$ Not measured. \\ Saltz $1997 \quad$ Not measured. \\ Toomey $2001 \quad$ Not measured. \\ Wallin $2003 \quad$ Not measured.
}

\section{Table 18. Results - Health promotion interventions}

Boots 1993

Injuries Not measured.

Behaviour BEHAVIOUR OF PATRONS

1) Self-reported behaviour of drinkers

For the experimental area the authors report that there was 'no significant change in attendance at 'safer' parties (i.e. those that adhered to the tips) between those who had heard of the intervention and others who had not'.

a) Provision of food; chi-squared $=2.543, \mathrm{df}=3, \mathrm{P}=0.4675$.

b) Provision of alternative drinks; chi-squared $=0.823, \mathrm{df}=3, \mathrm{P}=0.844$.

c) Reduction in service to intoxication; chi-squared $=5.844, \mathrm{df}=3, \mathrm{P}=0.1194$.

d) Provision of transport; chi-squared $=4.811, \mathrm{df}=3, \mathrm{P}=0.1862$.

Interventions in the alcohol server setting for preventing injuries (Review)

Copyright (c) 2008 The Cochrane Collaboration. Published by John Wiley \& Sons, Ltd 


\section{Table 18. Results - Health promotion interventions (Continued)}

In the control area is it reported that there was no significant pre-post difference, however no quantitative data were reported.

Knowledge

\section{DRINKERS' KNOWLEDGE}

In the experimental area there was no significant community-wide change in safe partying knowledge resulting from the campaign; chi2 $=2.254, \mathrm{df}=5, \mathrm{P}=0.813$. No significant pre-post difference found in the control area, no other quantitative data reported.

McLean 1994

Injuries Not measured.

Behaviour BEHAVIOUR OF PATRONS

1) Median $\mathrm{BAC}(\mathrm{mg} \%)$

This was 0.030 in both the experimental and control groups $(\mathrm{P}=0.415)$.

2) Percentage of patrons with a $\mathrm{BAC}>0.10$

This was $17.5 \%$ and $20.0 \%$ in the experimental and control groups respectively $(\mathrm{P}=0.509)$.

3) Percentage of patrons with a BAC $>0.15$

This was $7.5 \%$ and $7.8 \%$ in the experimental and control groups respectively $(\mathrm{P}=1.000)$.

SELF-REPORTED ALCOHOL CONSUMPTION

1) This was significantly less in the experimental group (38g) than the control (47g) with $P=0.01$.

2) Percentage of patrons with a measured $\mathrm{BAC}>0.05 \%$ who intended to drive

This was $6.8 \%$ in experimental and $7.8 \%$ in the control group $(\mathrm{P}=0.635)$.

Knowledge Not measured.

\section{Table 19. Results - Drink driving prevention services}

Lacey 2000

Injuries

ROAD TRAFFIC CRASHES

1) Injury crashes

These reduced by $15 \%$ in the experimental area after implementation of the programme $(t=-2.61$, reported as 'highly significant'), and there was no reduction in the control areas.

2) Fatal road traffic crashes

A before-and-after analysis of the ratio of the experimental area's fatal crashes to the comparison's fatal crashes, indicated that the ratio reduced from 0.78 to 0.60 , this was reported as not being statistically significant $(\mathrm{P}=0.29)$.

Behaviour Not measured.

Knowledge Not measured.

\section{Table 20. Results - Interventions targeting the server setting environment}

Casteel 2004

Injuries Post intervention period control versus experimental stores

Rate Ratios [adjusted for reported district crime] with 95\% CI and P values;

1) Robbery

5.4 (95\%CI 0.7-43) $\mathrm{P}=0.11$

2) Assault

3.4 (95\%CI 0.7-18) $\mathrm{P}=0.13$

Interventions in the alcohol server setting for preventing injuries (Review) 
Table 20. Results - Interventions targeting the server setting environment (Continued)

3) Shoplifting
5.6 (95\%CI 0.9-36) $\mathrm{P}=0.07$
4) All crime
4.6(95\%CI 1.7-12) $\mathrm{P}=0.01$
5) Injury
1.1 (95\%CI 0.1-10) $\mathrm{P}=0.93$
6) Police reports
2.7 (95\%CI $1.3-5.4) \mathrm{P}=0.01$.

Behaviour Not measured.

Knowledge Not measured.

Warburton 2000

Injuries

GLASSWARE RELATED INJURIES INFLICTED TO SERVING STAFF

98 staff experienced 115 injuries; 43 in control and 72 in intervention group.

The ratio of number of staff injured in the experimental group to number in the control was 1.72 (95\%CI 1.15 , 2.59) ( $\neg 70 \%$ greater risk of injury in experimental group). Relative risk adjusted for people at risk was 1.48 (95\%CI 1.02, 2.15). ( $-50 \%$ greater risk of injury in experimental group). Relative risk adjusted for hours worked was 1.57 (95\%CI 1.08, 2.29). ( $-60 \%$ greater risk of injury in experimental group)

$\mathrm{P}<0.05$ (all CIs exclude the null hypothesis). Most injury, $86 \%$ and $89 \%$ in control and experimental bars respectively, was inflicted to the hands.

Behaviour Not measured.

Knowledge Not measured.

\section{Table 21. Results - Server setting management/policy interventions}

Felson 1997

Injuries SERIOUS ASSAULT RATES

The study reports that before intervention, the experimental area's serious assault rate was $52 \%$ higher than the comparison rate.

Knowledge Not measured.

Behaviour Not measured.

\section{GRAPHSANDOTHER TABLES}

This review has no analyses.

\section{INDEX TERMS}

\section{Medical Subject Headings (MeSH)}

Accident Prevention [* methods]; Accidents, Traffic [prevention \& control]; *Alcohol Drinking [adverse effects]; Automobile Driving; Health Promotion; Wounds and Injuries [* prevention \& control]

\section{MeSH check words}

Humans

Interventions in the alcohol server setting for preventing injuries (Review) 


\section{COVER SHEET}

Title

Authors

Contribution of author(s)

Issue protocol first published

Review first published

Date of most recent amendment

Date of most recent

SUBSTANTIVE amendment

What's New

Date new studies sought but none found

Date new studies found but not yet included/excluded

Date new studies found and included/excluded

Date authors' conclusions section amended

Contact address

DOI

Cochrane Library number

Editorial group

Editorial group code
Interventions in the alcohol server setting for preventing injuries

Ker K, Chinnock P

KK wrote the protocol, ran the searches, screened records, assessed full texts for inclusion, data extracted and wrote the review.

PC screened records, assessed full texts for inclusion and helped with data extraction. PC also commented on drafts of the protocol and review.

$2005 / 2$

$2006 / 2$

17 March 2006

26 January 2006

Information not supplied by author

Information not supplied by author

Information not supplied by author

Information not supplied by author

Information not supplied by author

Miss Katharine Ker

Co-ordinator, Cochrane Injuries Group

Nutrition \& Public Health Intervention Research Unit

London School of Hygiene and Tropical Medicine

Room 280, North Courtyard

Keppel Street

London

WC1E 7HT

UK

E-mail: katharine.ker@lshtm.ac.uk

Tel: +44 (0) 2079588135

Fax: +44 (0) 2079588111

10.1002/14651858.CD005244.pub2

CD005244

Cochrane Injuries Group

HM-INJ 